\title{
Synthesis of a Core Arabinomannan
}

\section{Oligosaccharide of Mycobacterium Tuberculosis}

\author{
Alexandra Hölemann, Bridget L. Stocker and Peter H. Seeberger*
}

\section{Supporting Information - Part V}

Arabinose Building Blocks, Arabinan Hexasaccharides and

\section{Arabinomannans}

\section{Table of Contents}

${ }^{1} \mathrm{H}$ NMR spectrum of compound 39

${ }^{1} \mathrm{H}$ NMR and ${ }^{13} \mathrm{C}$ NMR spectra of compound $\mathbf{4 0}$

${ }^{1} \mathrm{H}$ NMR and ${ }^{13} \mathrm{C}$ NMR spectra of compound $\mathbf{1 0}$

${ }^{1} \mathrm{H}$ NMR and ${ }^{13} \mathrm{C}$ NMR spectra of compound 41

S8-S9

${ }^{1} \mathrm{H}$ NMR and ${ }^{13} \mathrm{C}$ NMR spectra of compound 42

${ }^{1} \mathrm{H}$ NMR and ${ }^{13} \mathrm{C}$ NMR spectra of compound $\mathbf{1 1}$

${ }^{1} \mathrm{H}$ NMR and ${ }^{13} \mathrm{C}$ NMR spectra of compound 43

${ }^{1} \mathrm{H}$ NMR and ${ }^{13} \mathrm{C}$ NMR spectra of compound 12a

${ }^{1} \mathrm{H}$ NMR and ${ }^{13} \mathrm{C}$ NMR spectra of pent-4-enyl 2-O-benzoyl-3-O-benzyl- $\alpha-\mathrm{D}-\mathrm{S} 20-\mathrm{S} 21$ arabinofuranoside 
${ }^{1} \mathrm{H}$ NMR and ${ }^{13} \mathrm{C}$ NMR spectra of compound $\mathbf{4 4}$

${ }^{1} \mathrm{H}$ NMR and ${ }^{13} \mathrm{C}$ NMR spectra of compound 45

${ }^{1} \mathrm{H}$ NMR and ${ }^{13} \mathrm{C}$ NMR spectra of compound 46

S26-S27

${ }^{1} \mathrm{H}$ NMR and ${ }^{13} \mathrm{C}$ NMR spectra of compound 47

S28-S29

${ }^{1} \mathrm{H}$ NMR and ${ }^{13} \mathrm{C}$ NMR spectra of compound 48

S30-S31

${ }^{1} \mathrm{H}$ NMR and ${ }^{13} \mathrm{C}$ NMR spectra of compound 49

S32-S33

${ }^{1} \mathrm{H}$ NMR and ${ }^{13} \mathrm{C}$ NMR spectra of compound 4

S34-S35

${ }^{1} \mathrm{H}$ NMR and ${ }^{13} \mathrm{C}$ NMR spectra of compound 5

S36-S37

${ }^{1} \mathrm{H}$ NMR and ${ }^{13} \mathrm{C}$ NMR spectra of compound $\mathbf{5 0}$

S38-S39

${ }^{1} \mathrm{H}$ NMR spectrum of compound $\mathbf{1 5}$

S40

${ }^{1} \mathrm{H}$ NMR and ${ }^{13} \mathrm{C}$ NMR spectra of pent-4-enyl 5-O-(5-O-(5-O-(2-O-benzoyl-3- $\mathrm{S} 41-\mathrm{S} 42$ $O$-benzyl-5-O-triisopropylsilyl- $\alpha$-D-arabinofuranosyl)-2-O-benzoyl-3-O-(5-O-(2$O$-benzoyl-3-O-benzyl-5-O-triisopropylsilyl- $\alpha$-D-arabinofuranosyl)-2-Obenzoyl-3-O-benzyl- $\alpha$-D-arabinofuranosyl)- $\alpha$-D-arabinofuranosyl)-2-O-benzoyl3-O-benzyl- $\alpha$-D-arabinofuranosyl)-2-O-benzoyl-3-O-benzyl- $\alpha$-Darabinofuranoside

${ }^{1} \mathrm{H}$ NMR and ${ }^{13} \mathrm{C}$ NMR spectra of compound 6 S43-S44

${ }^{1} \mathrm{H}$ NMR and ${ }^{13} \mathrm{C}$ NMR spectra of compound $\mathbf{5 1}$ S45-S46

${ }^{1} \mathrm{H}$ NMR spectrum of compound $\mathbf{1}$

${ }^{1} \mathrm{H}$ NMR and ${ }^{13} \mathrm{C}$ NMR spectra of compound 52

${ }^{1} \mathrm{H}$ NMR and ${ }^{13} \mathrm{C}$ NMR spectra of compound 53

${ }^{1} \mathrm{H}$ NMR and ${ }^{13} \mathrm{C}$ NMR spectra of compound 54 


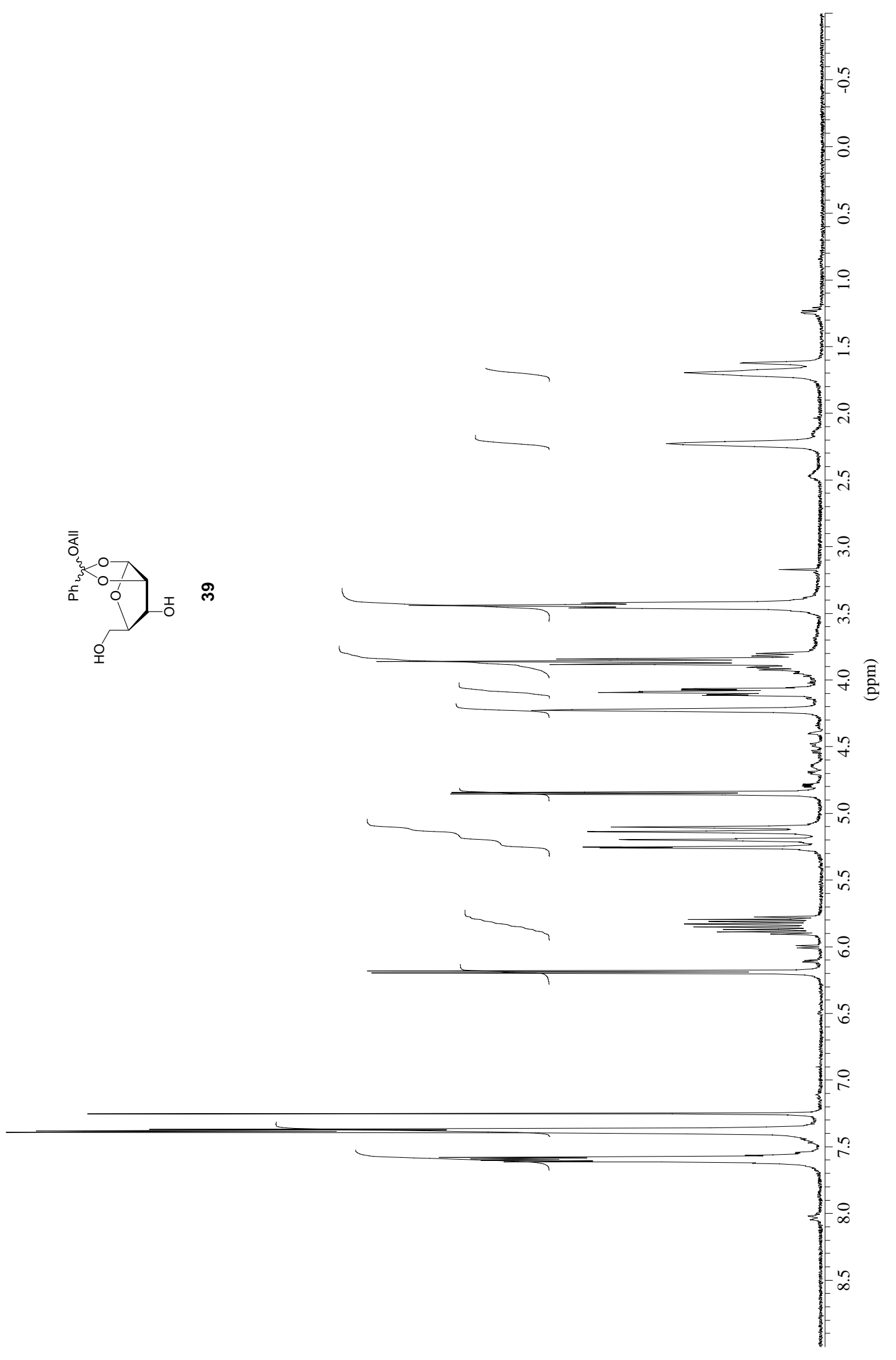




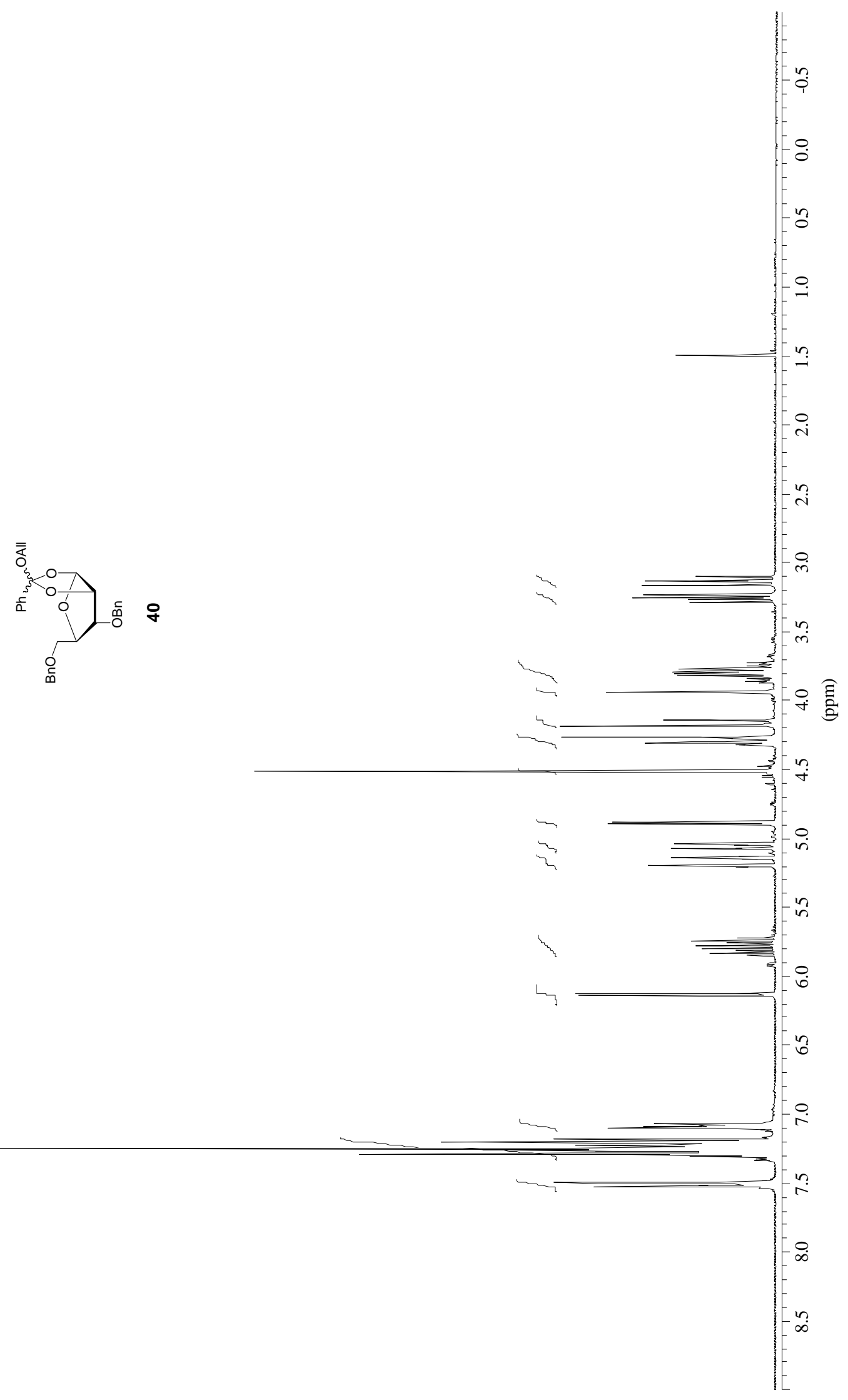




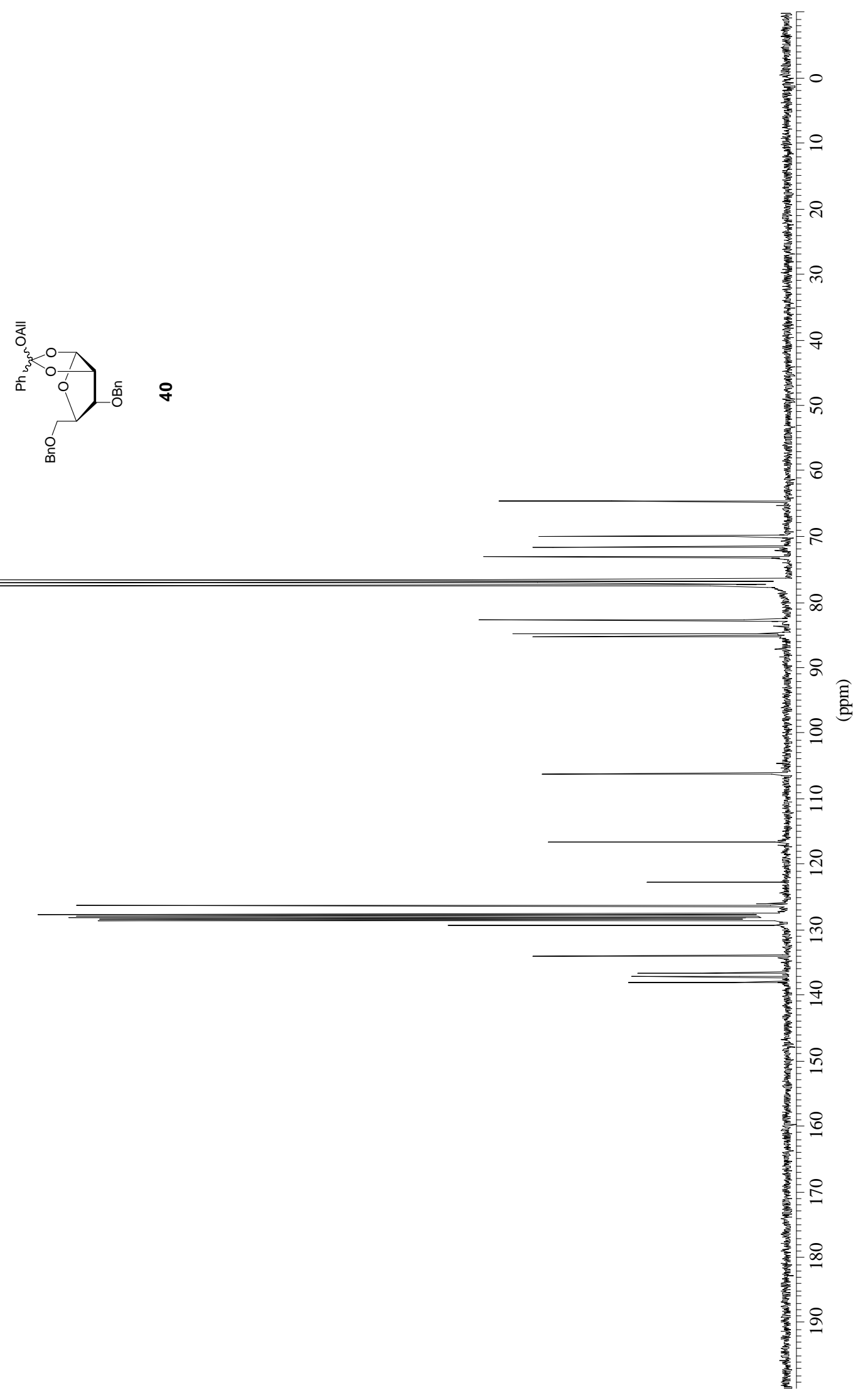




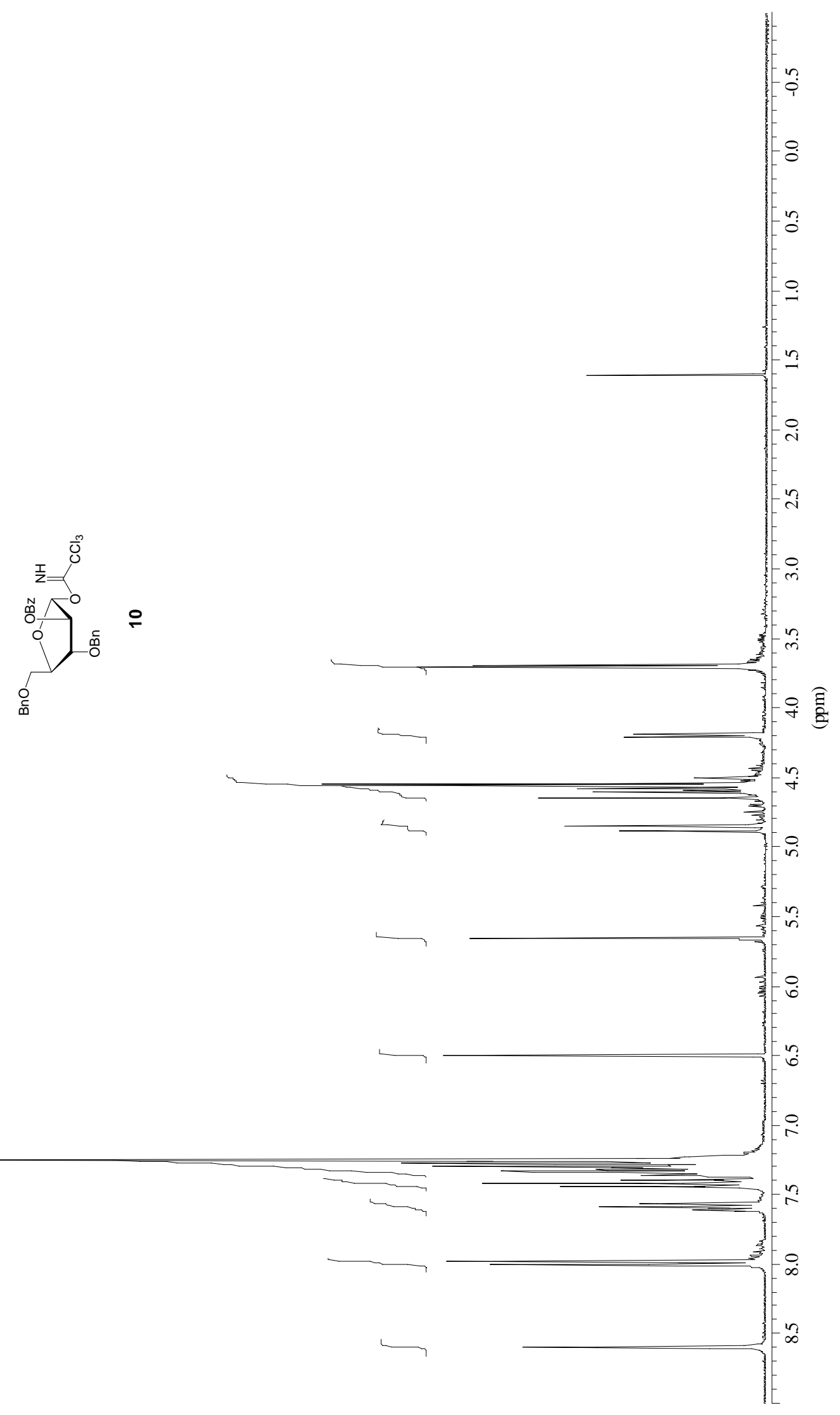




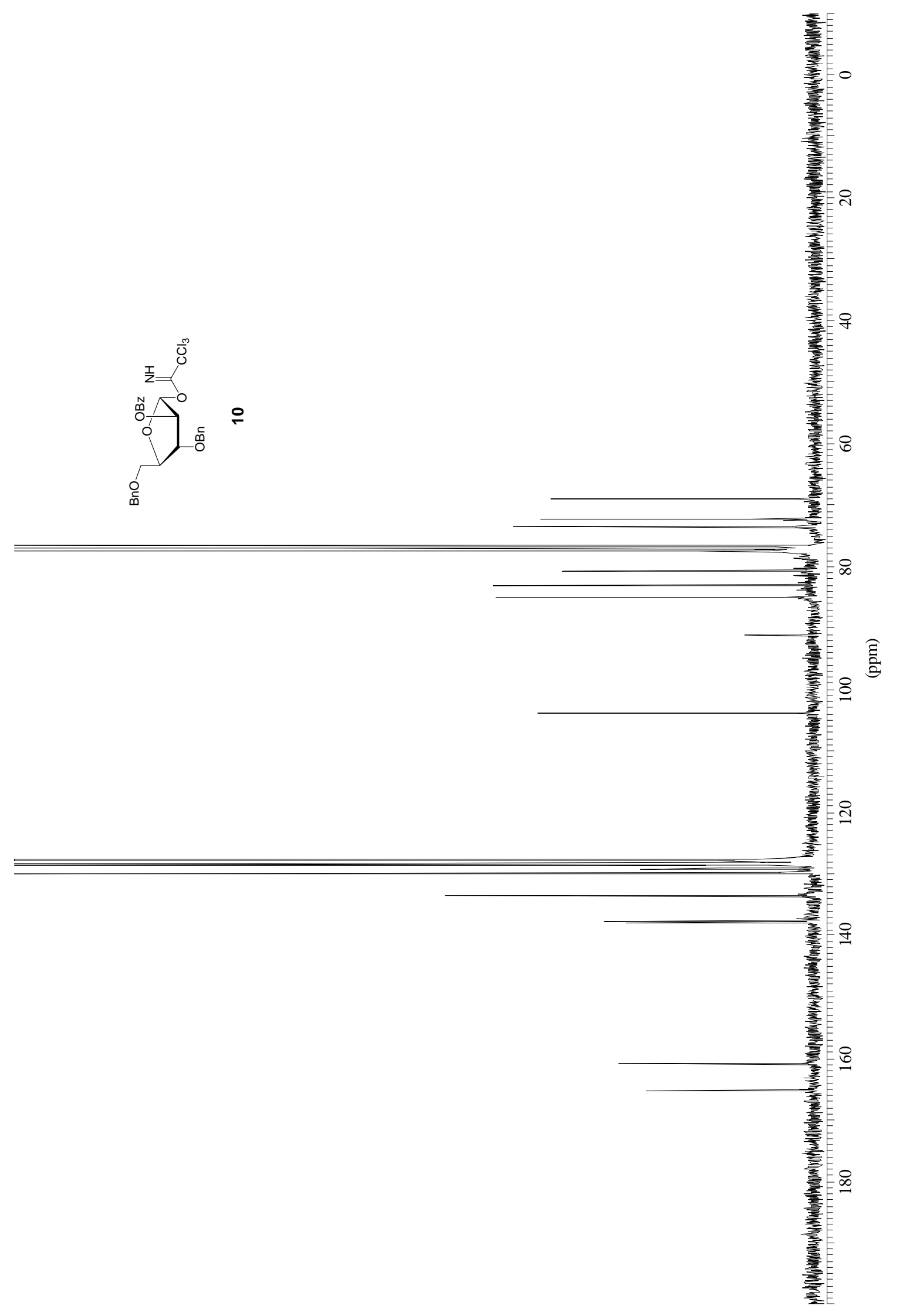




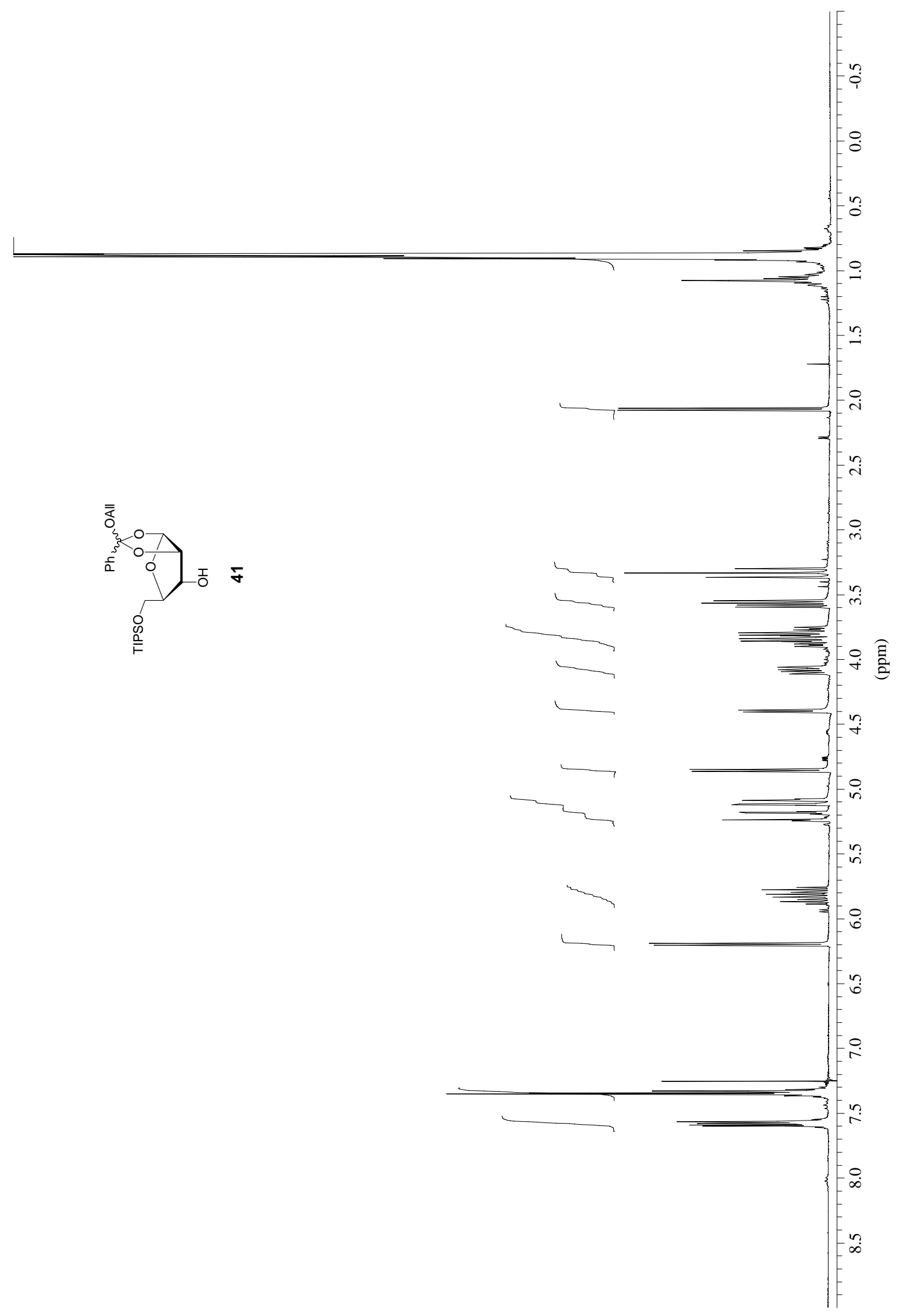




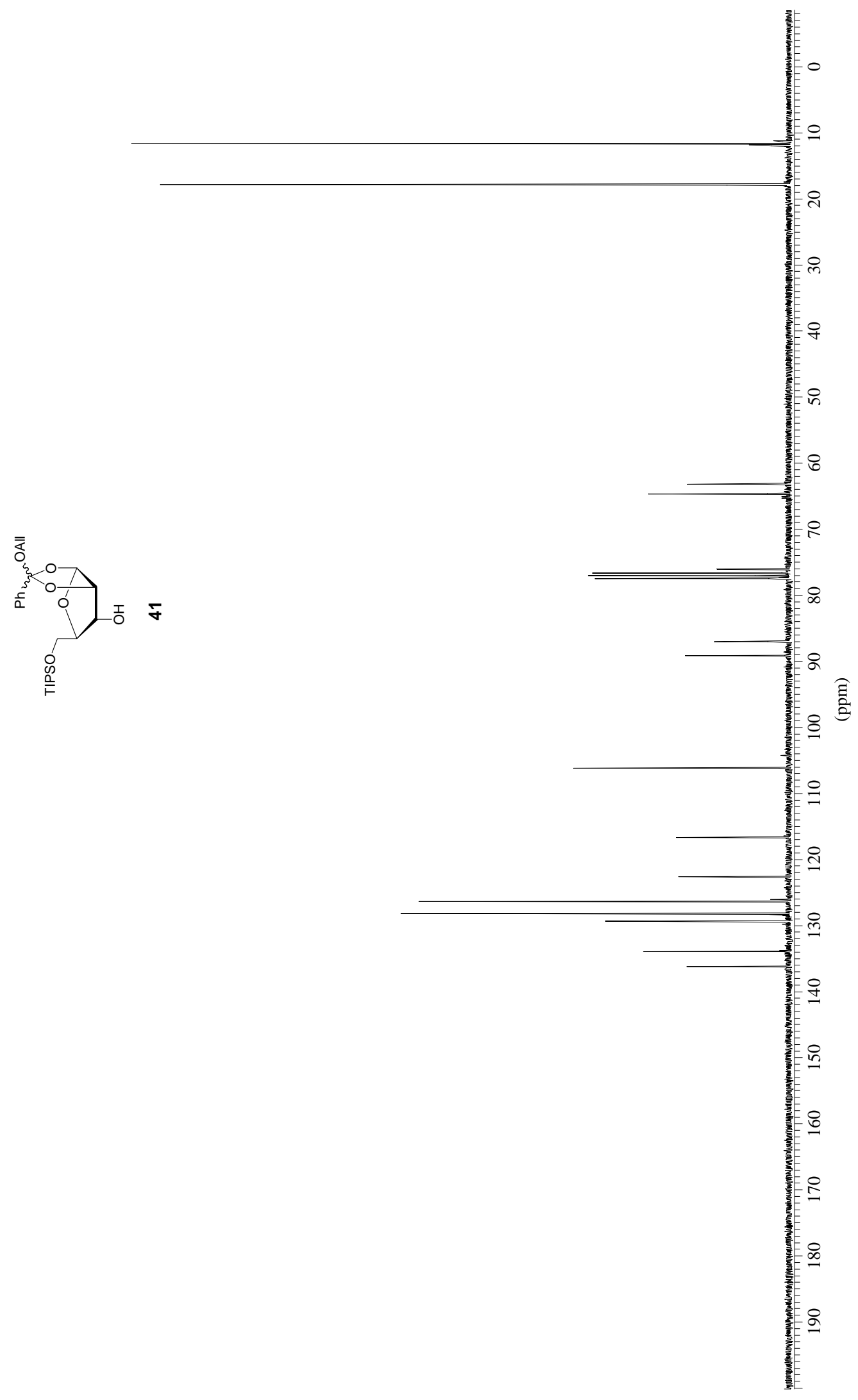




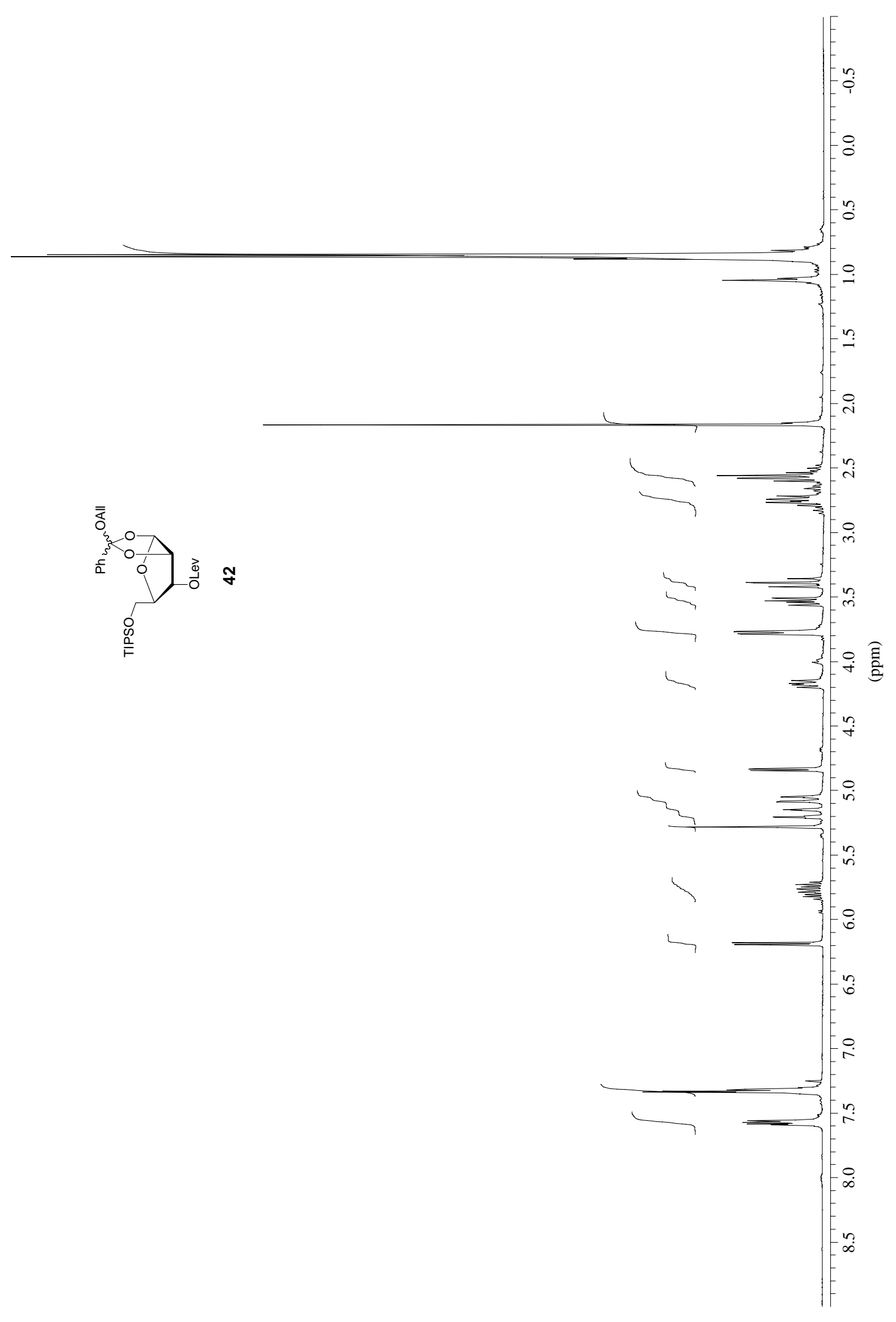




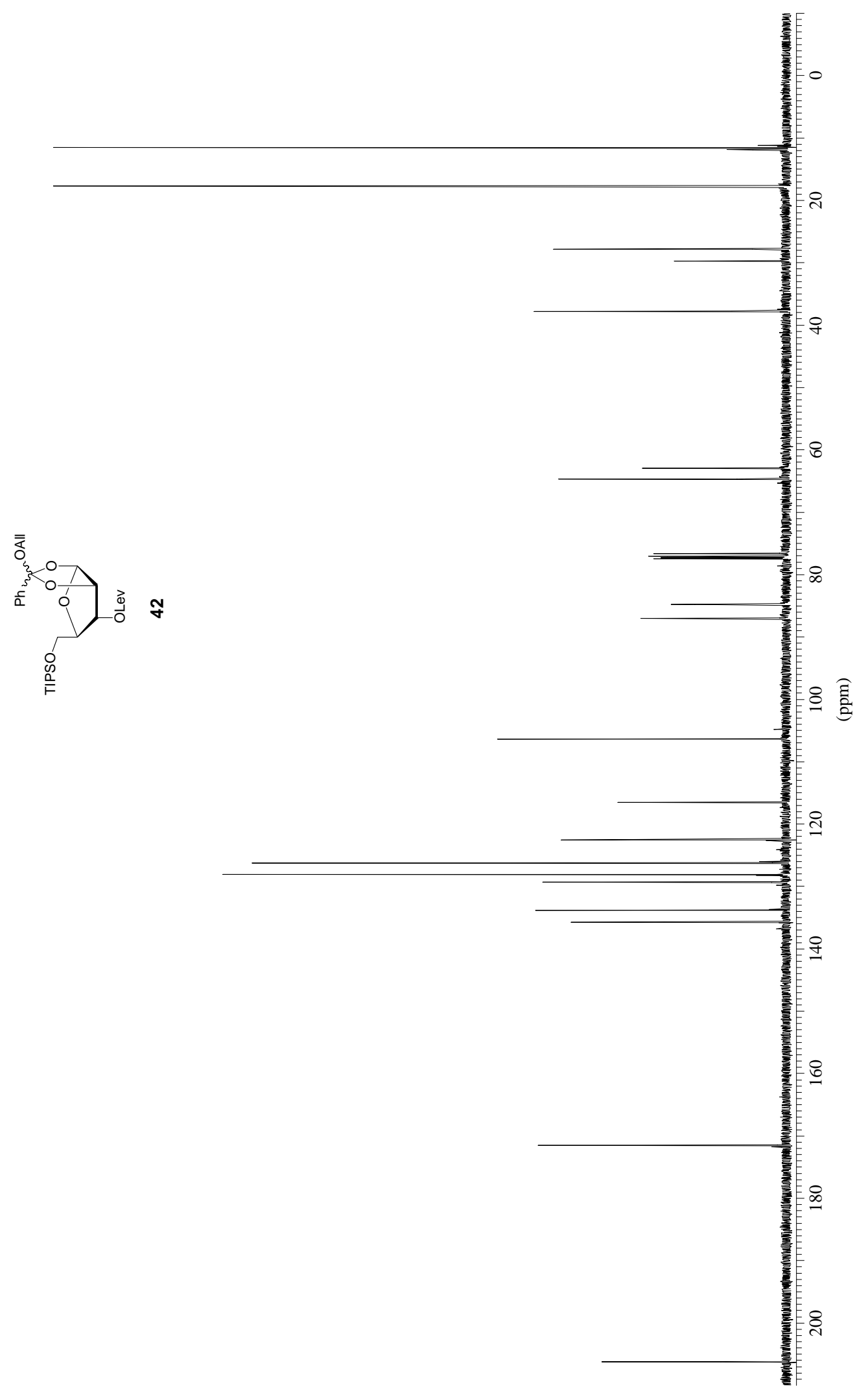

S11 File\#5 


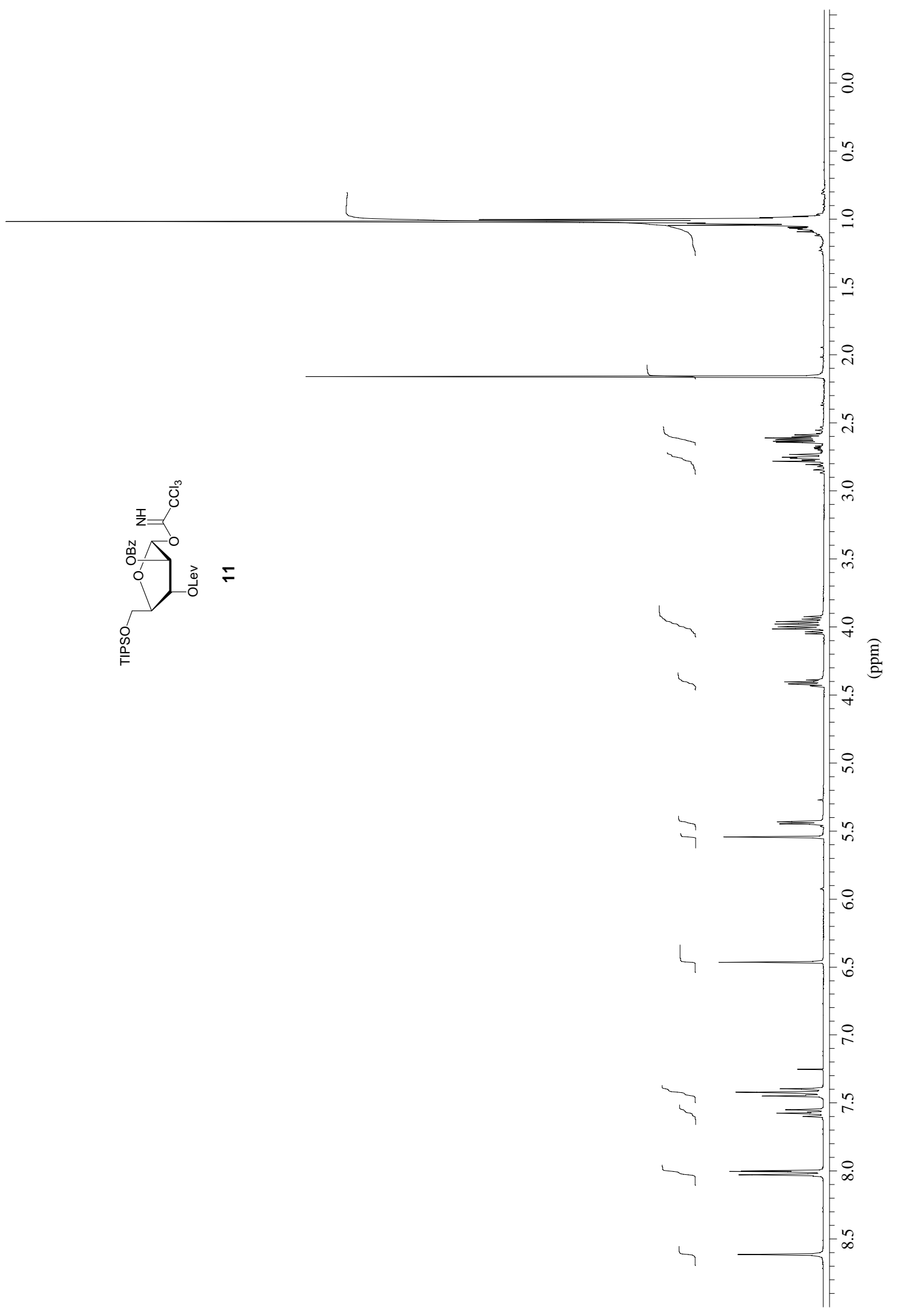




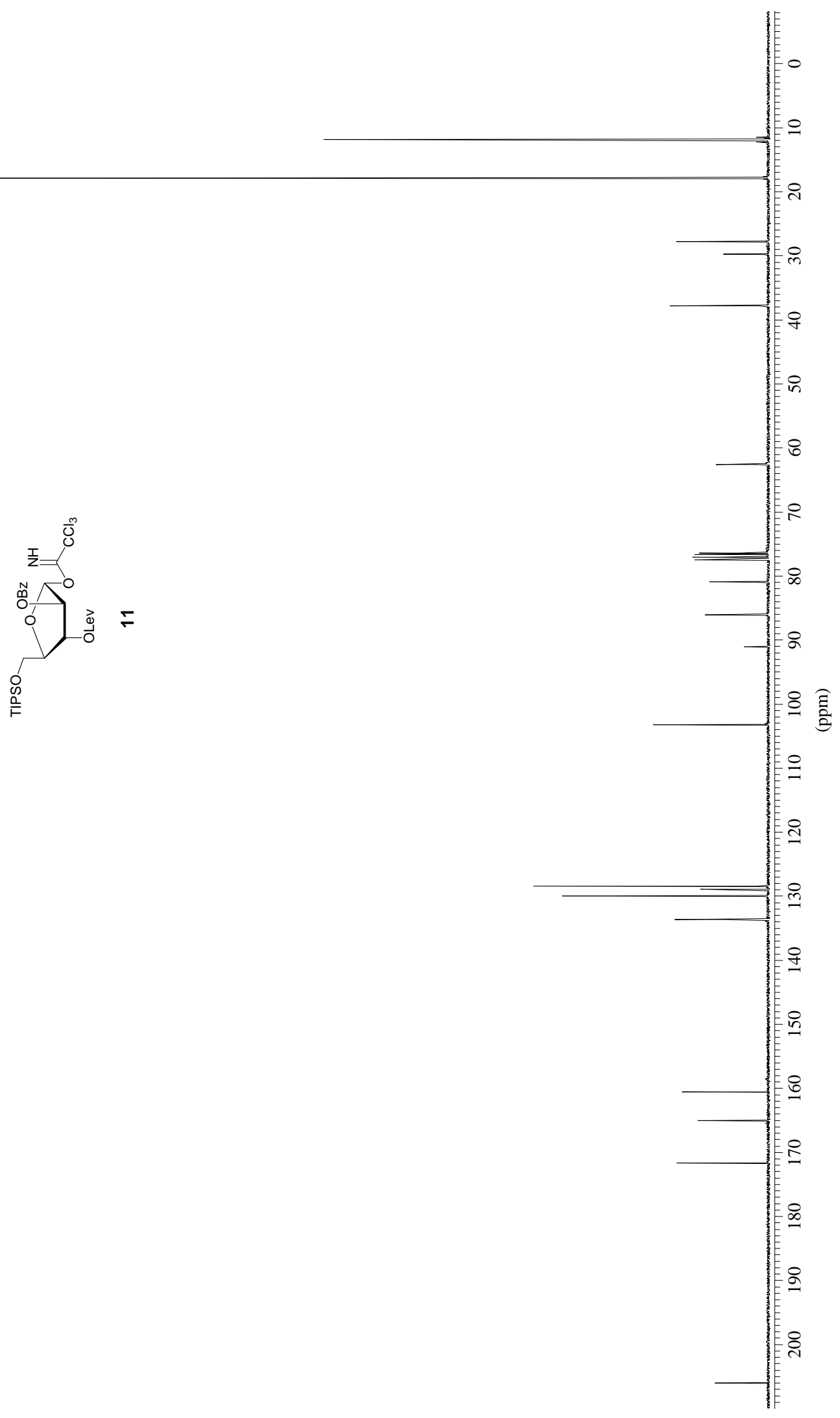




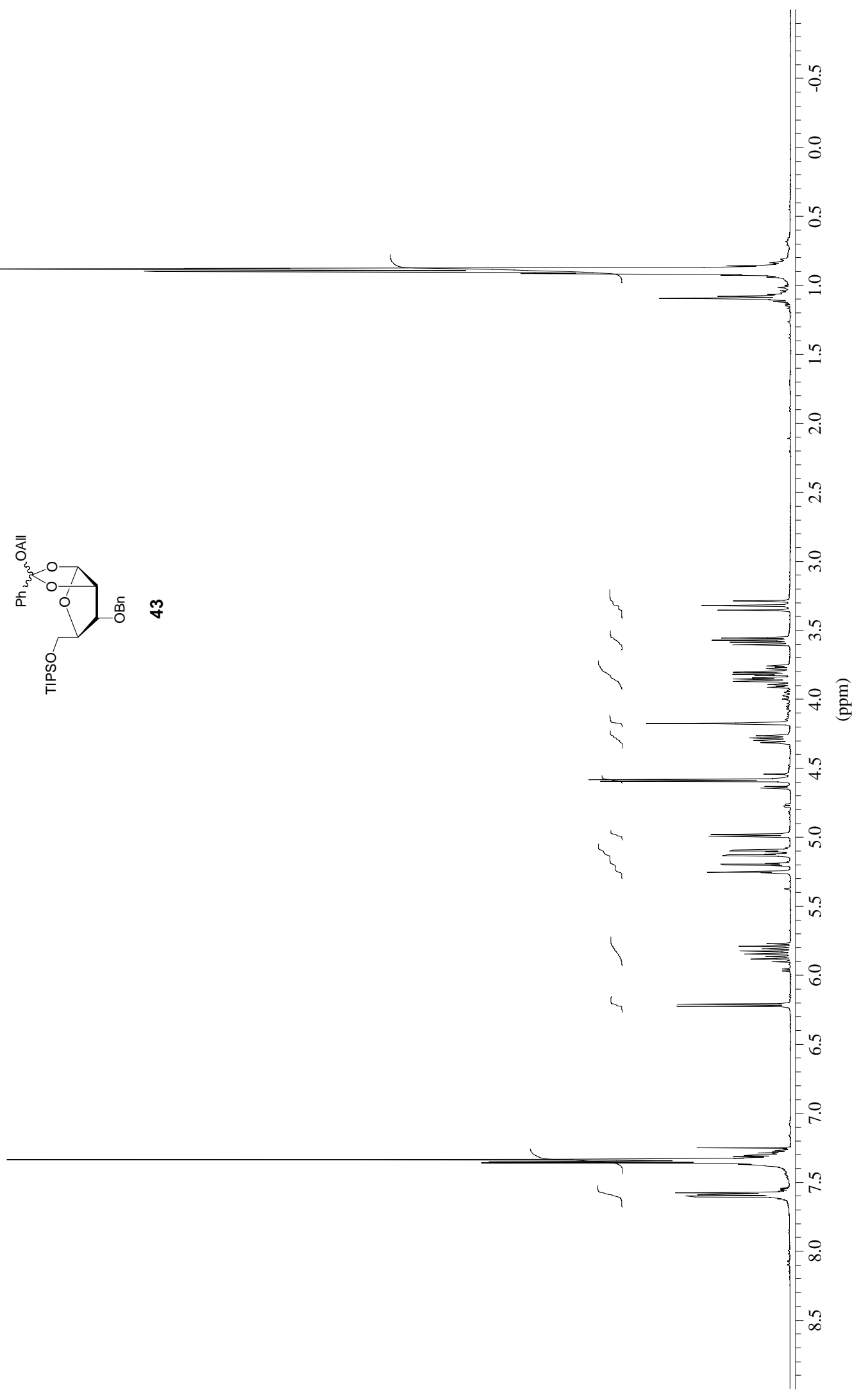




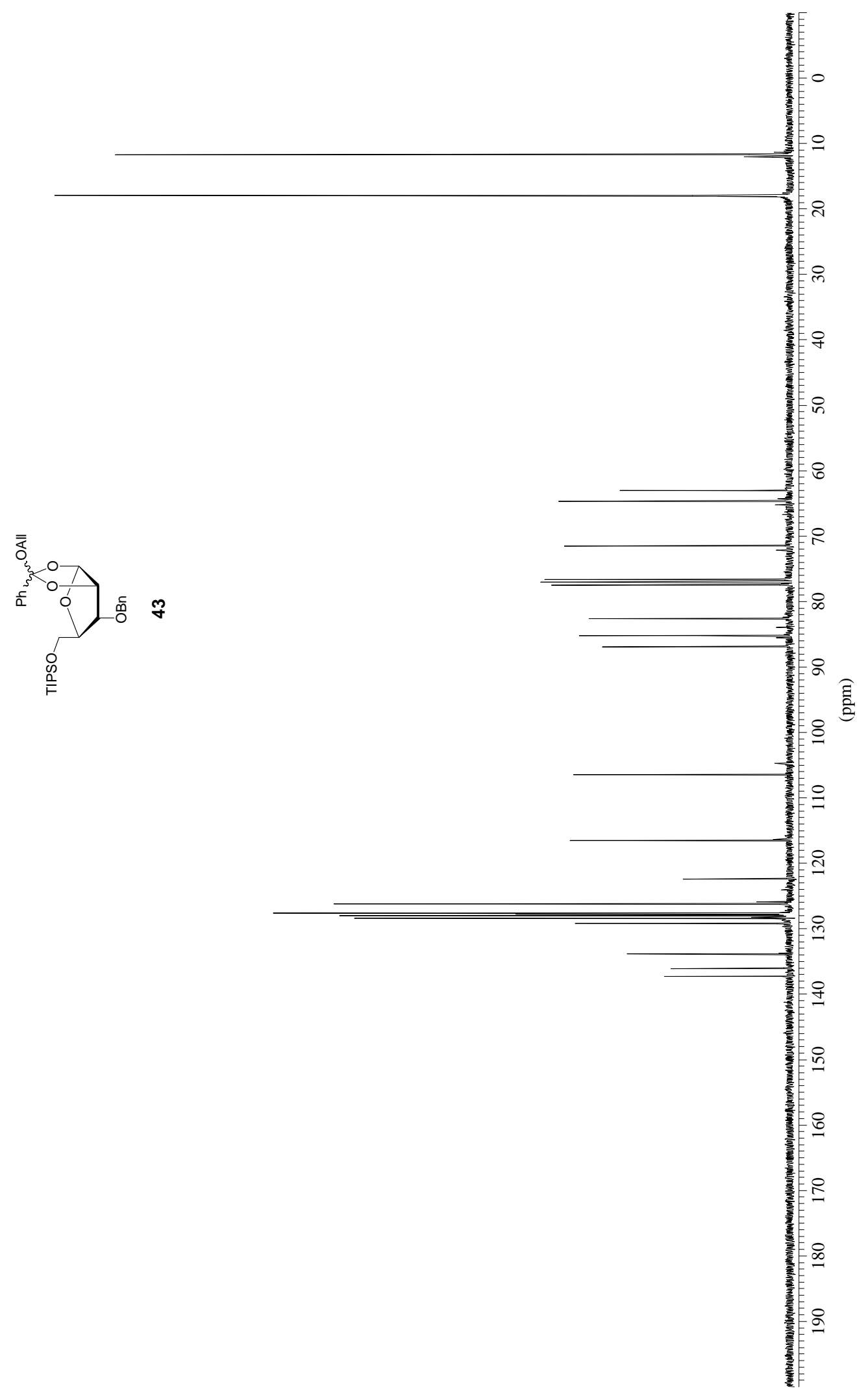




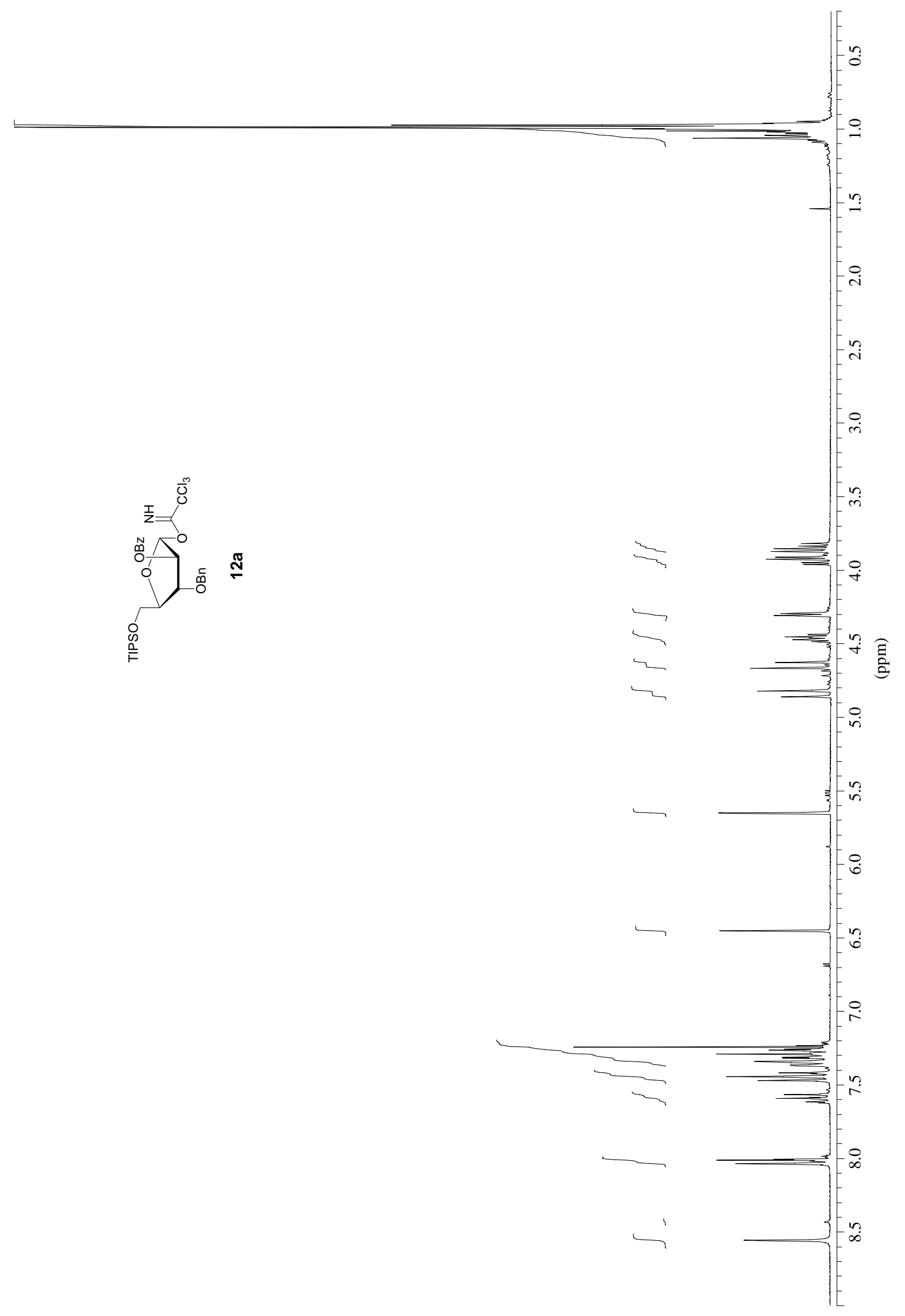




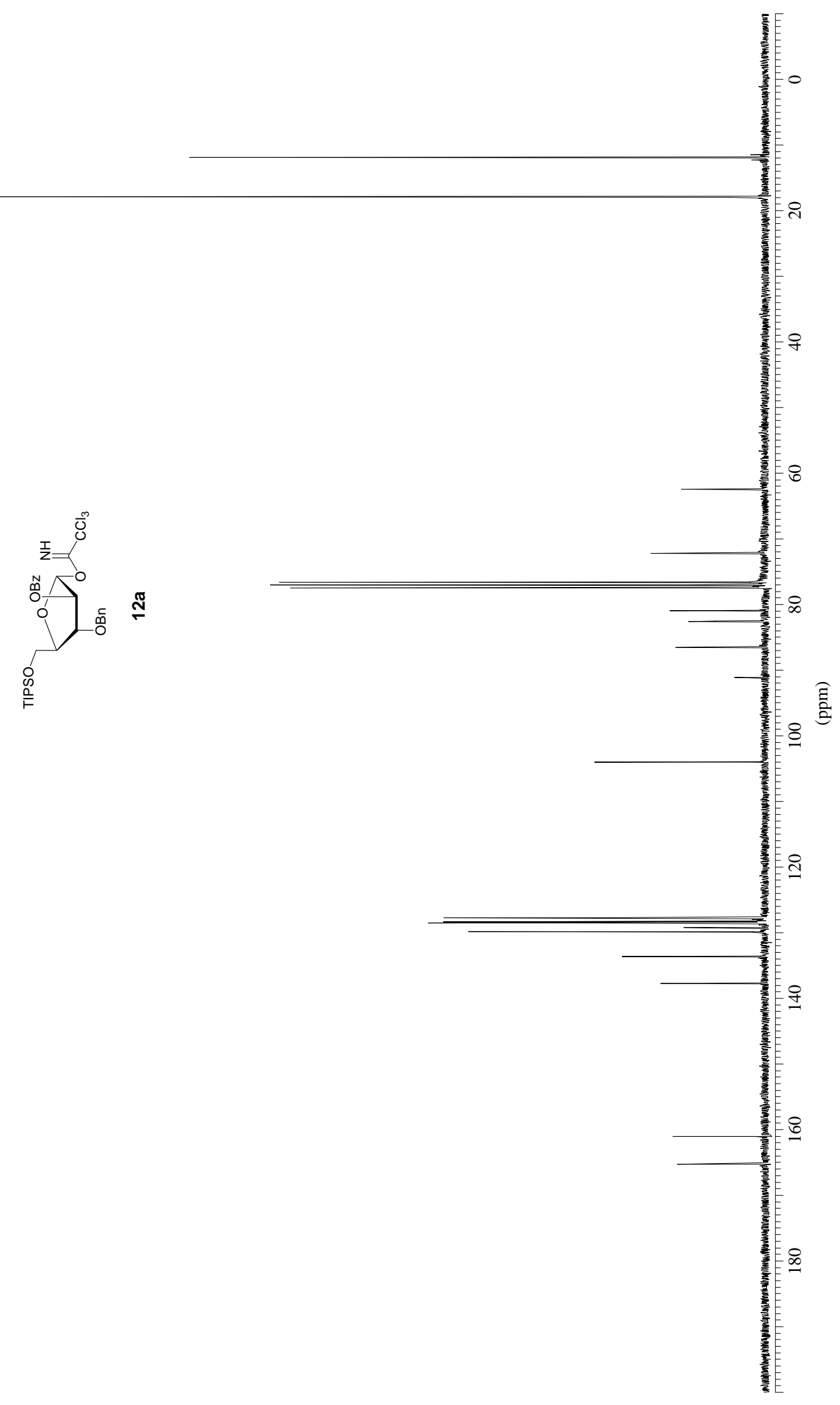




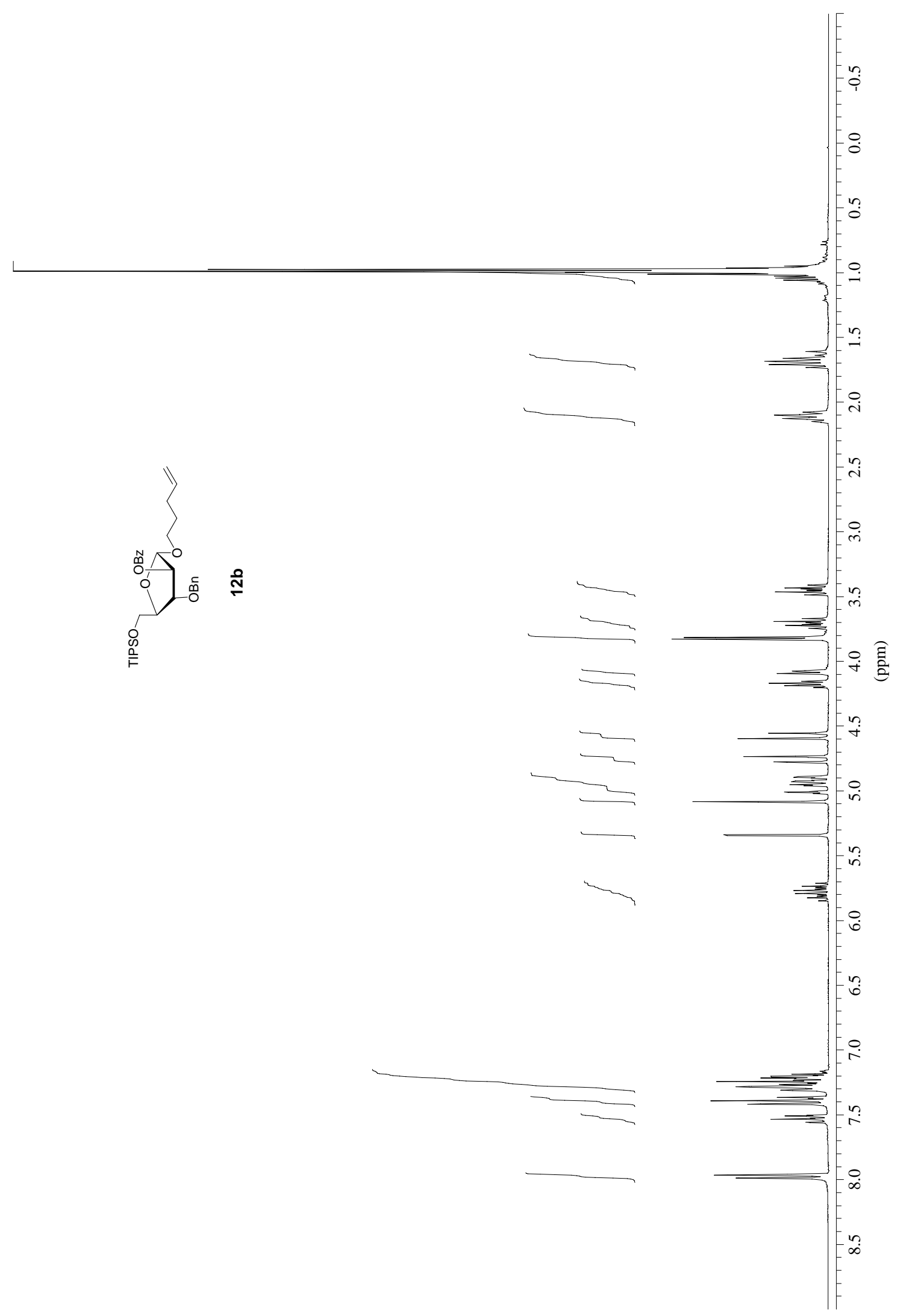




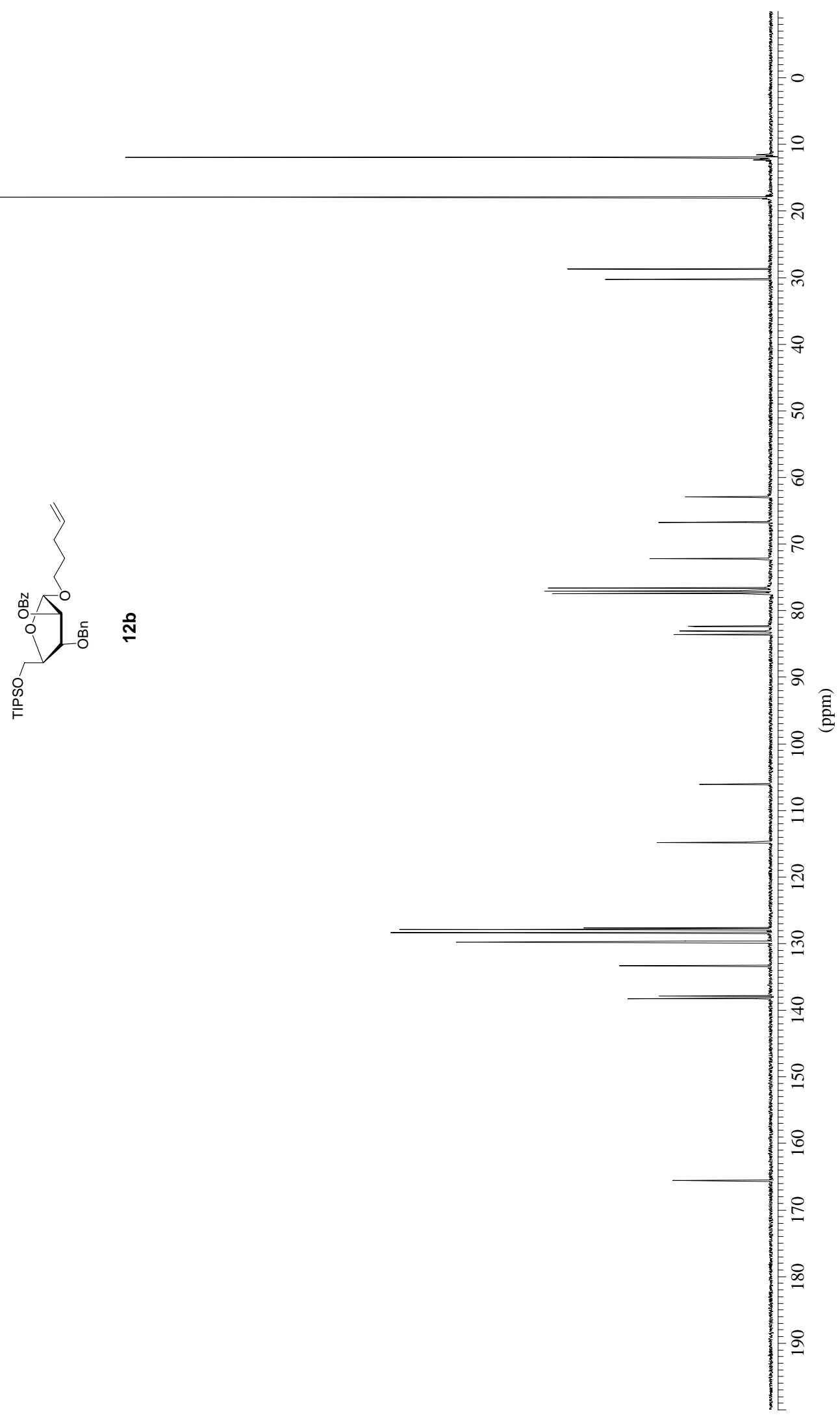




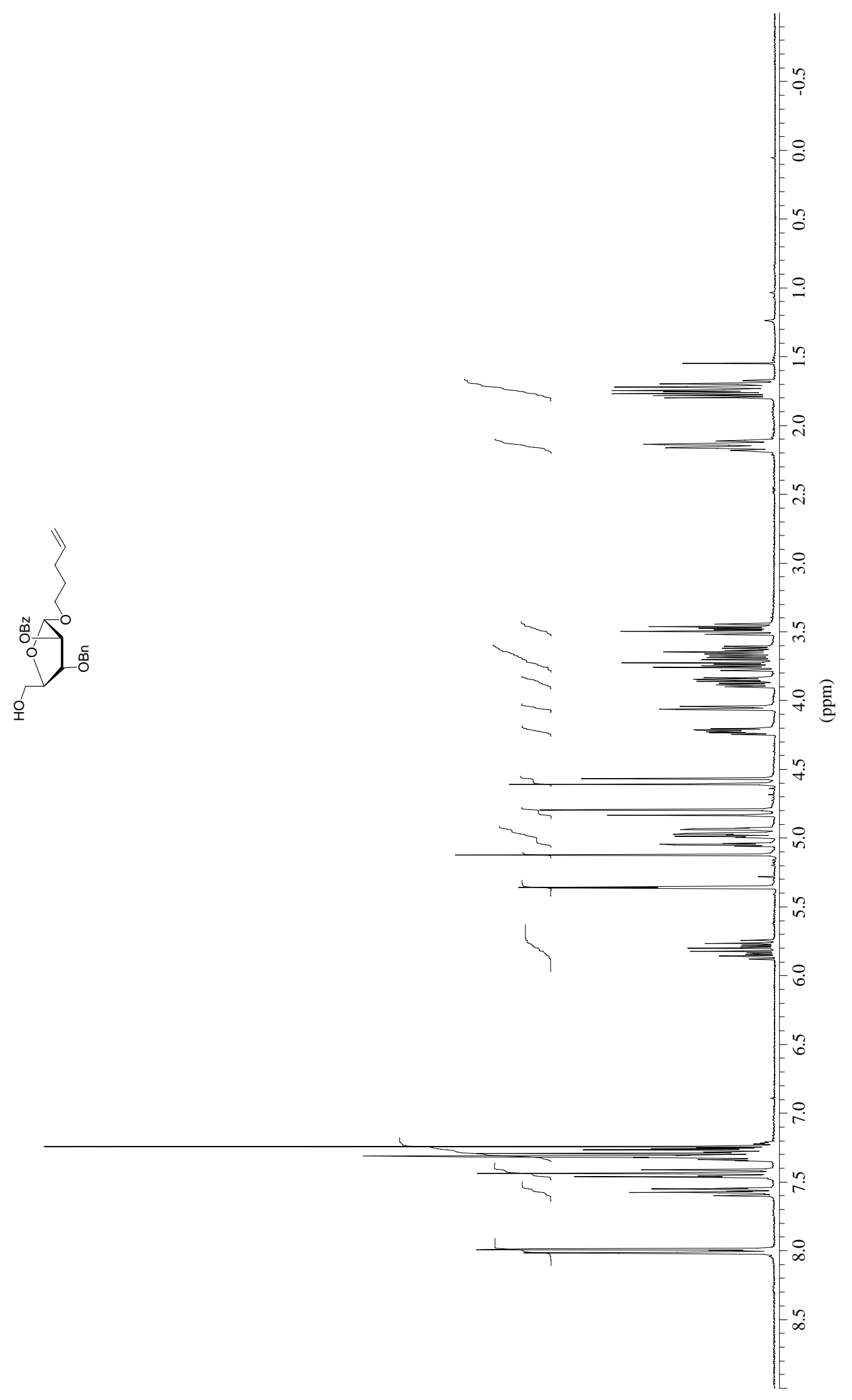




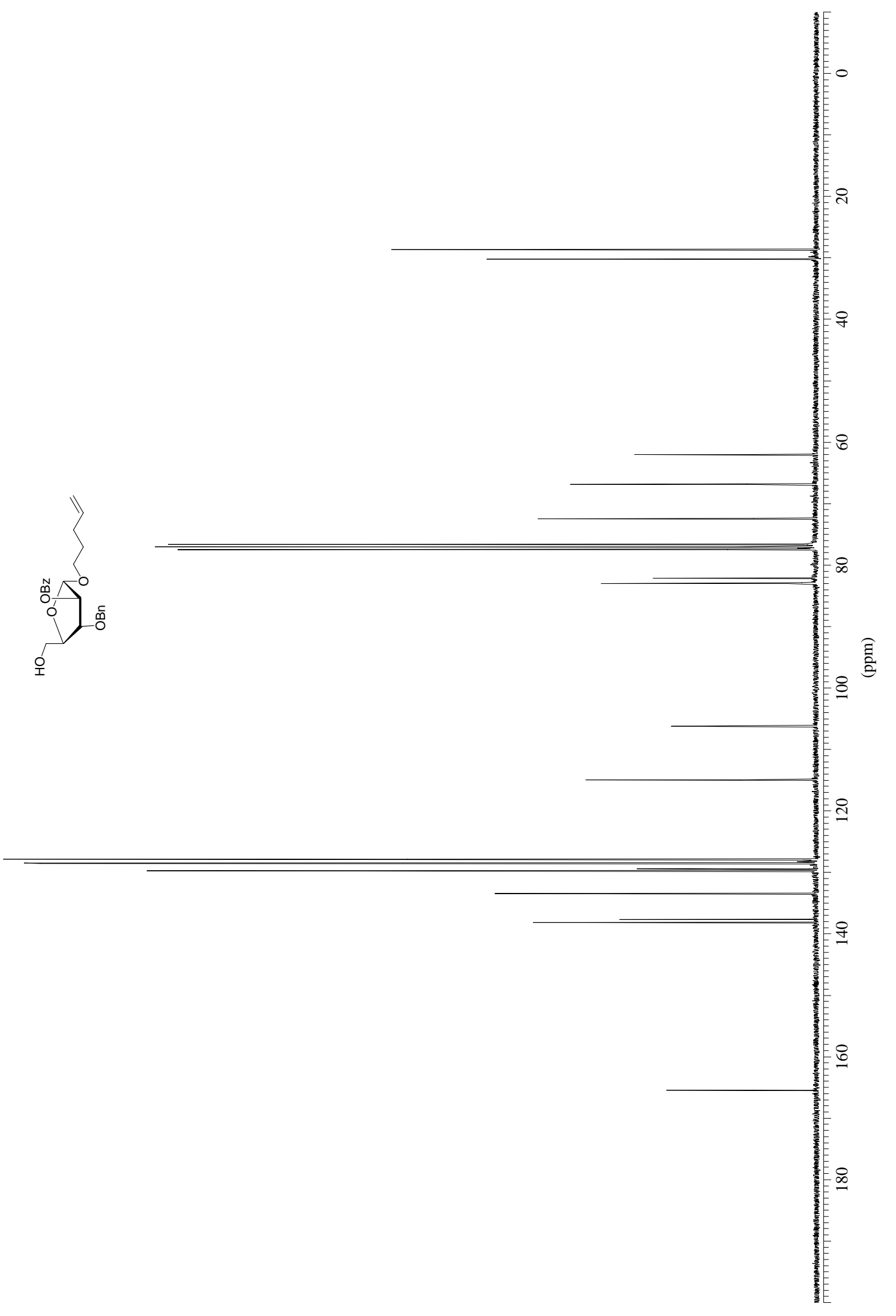




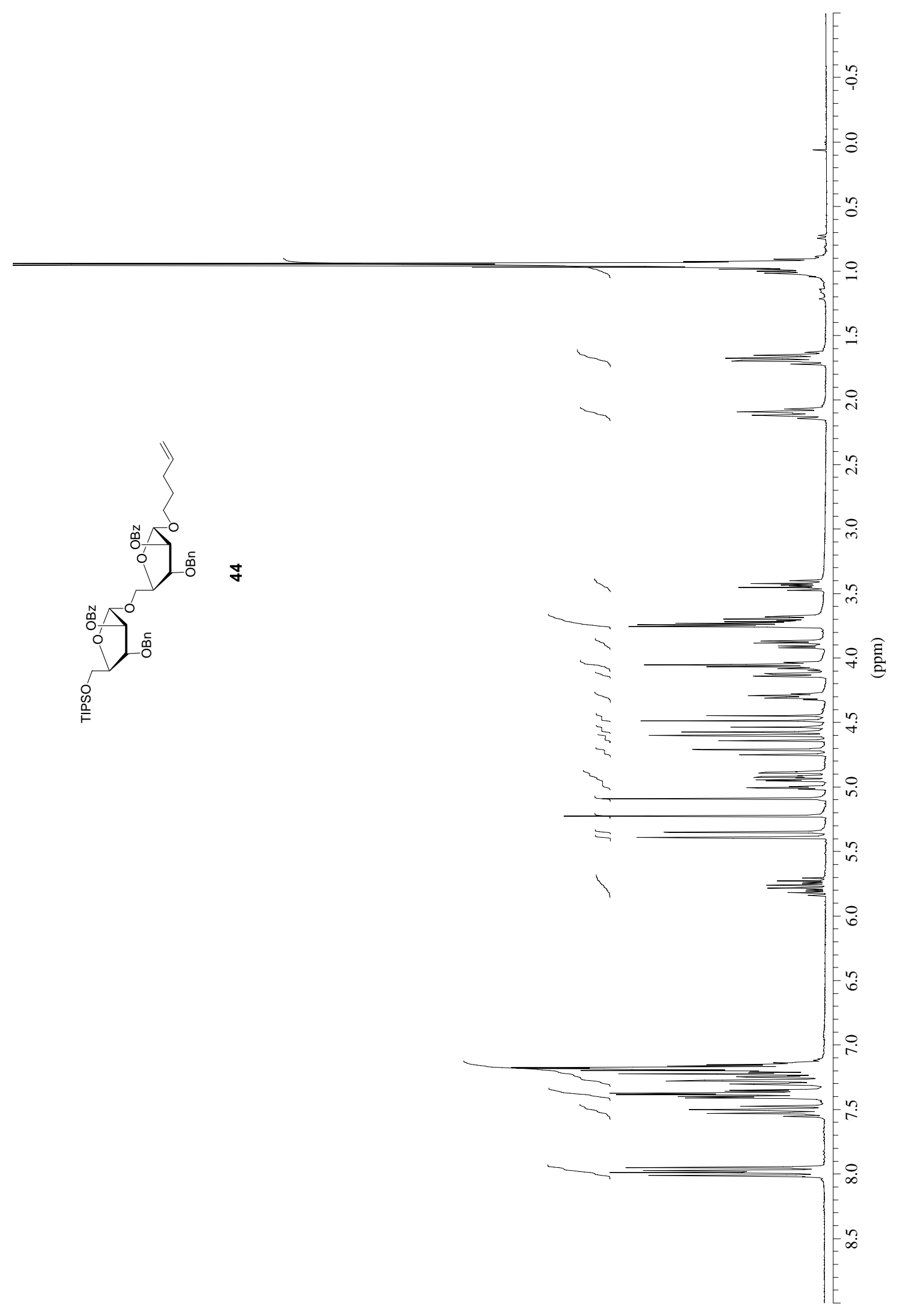




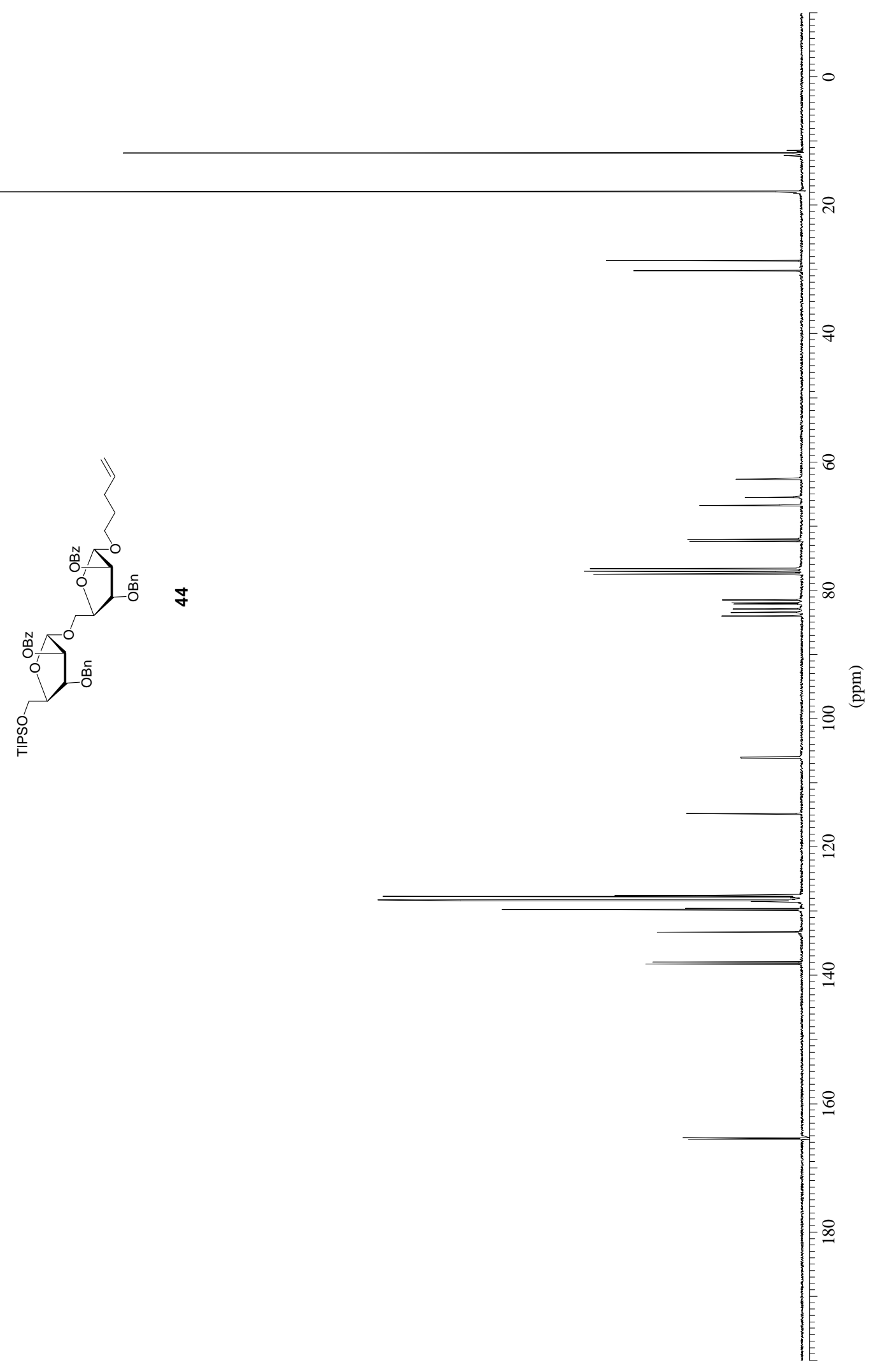




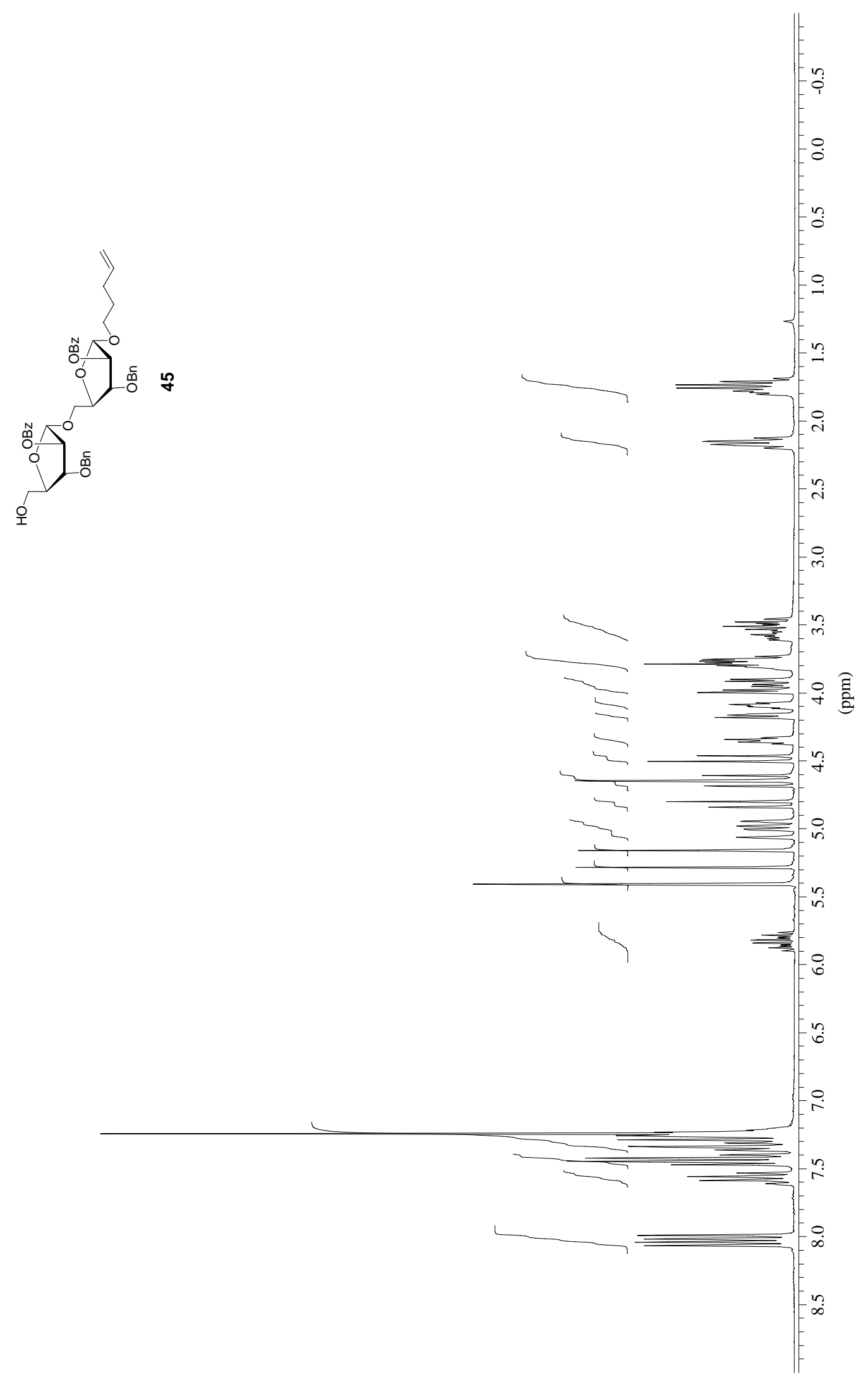




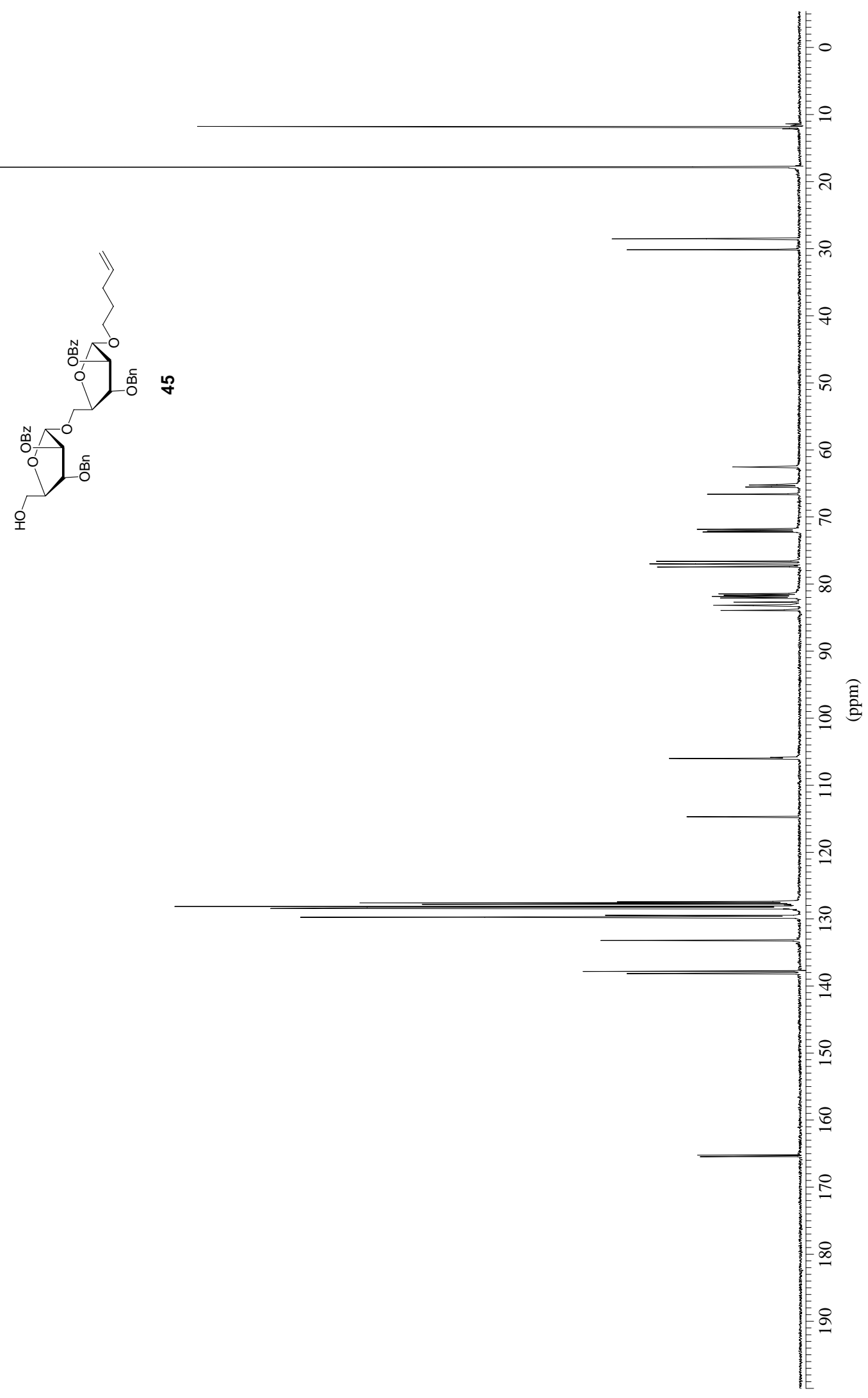




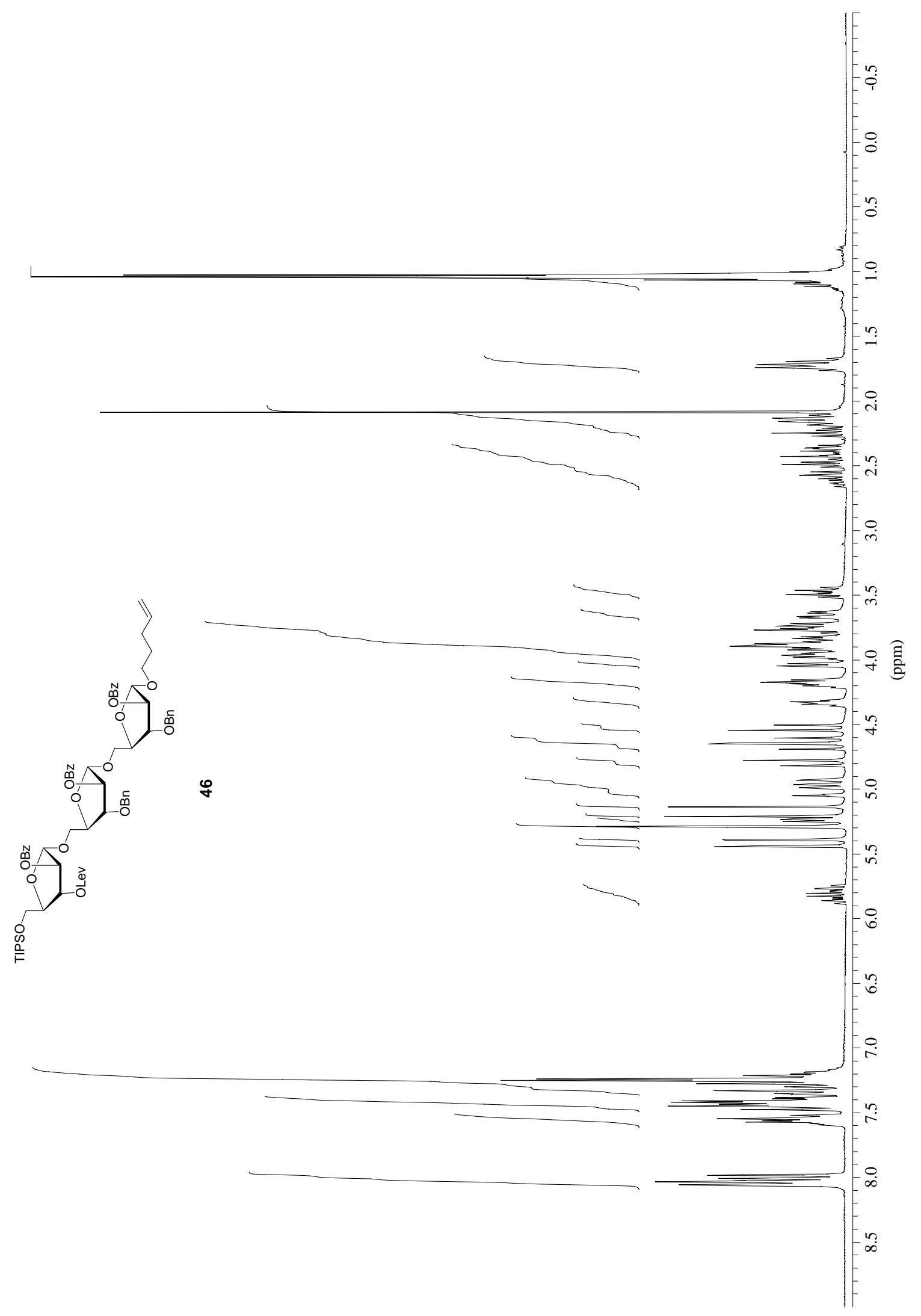




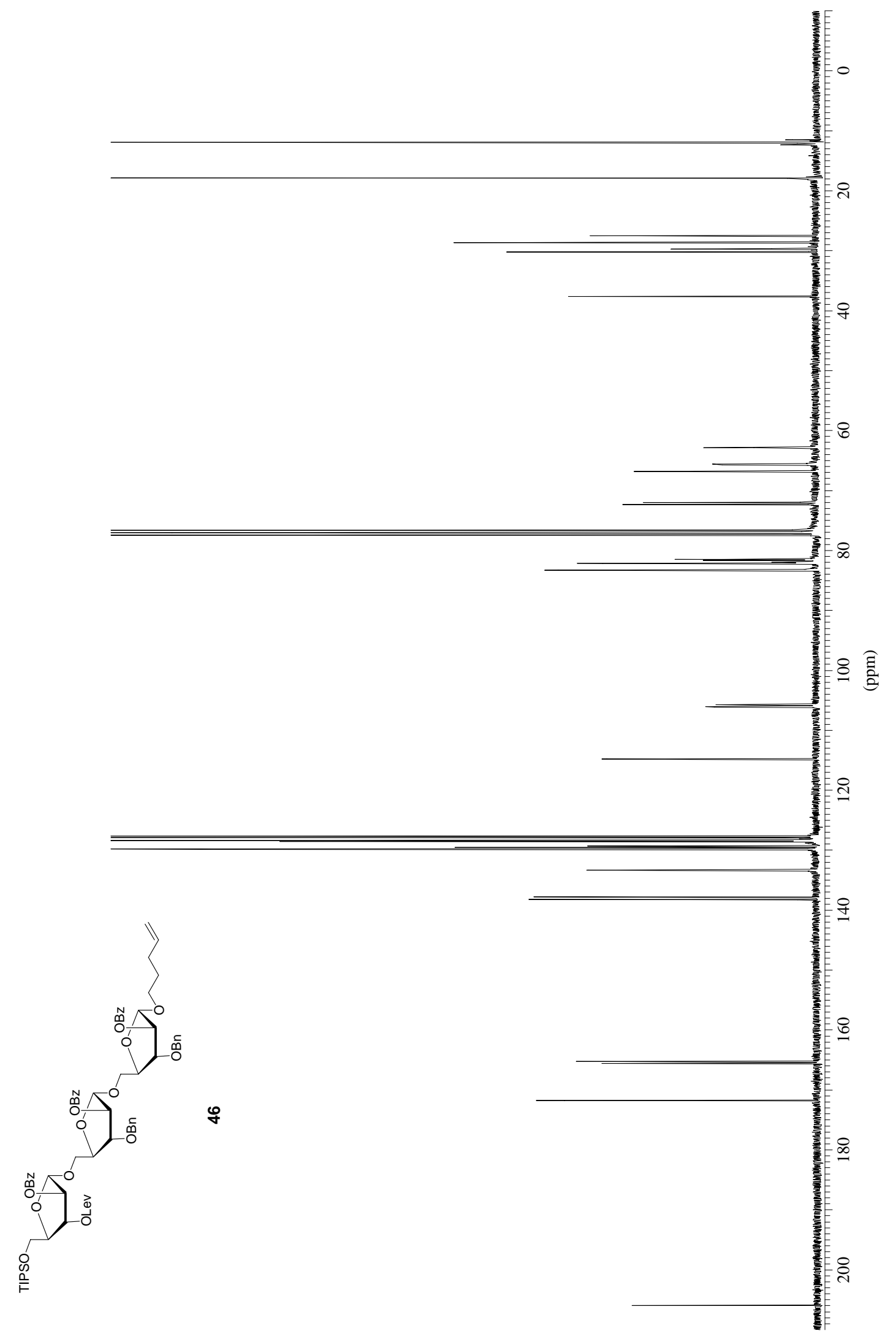




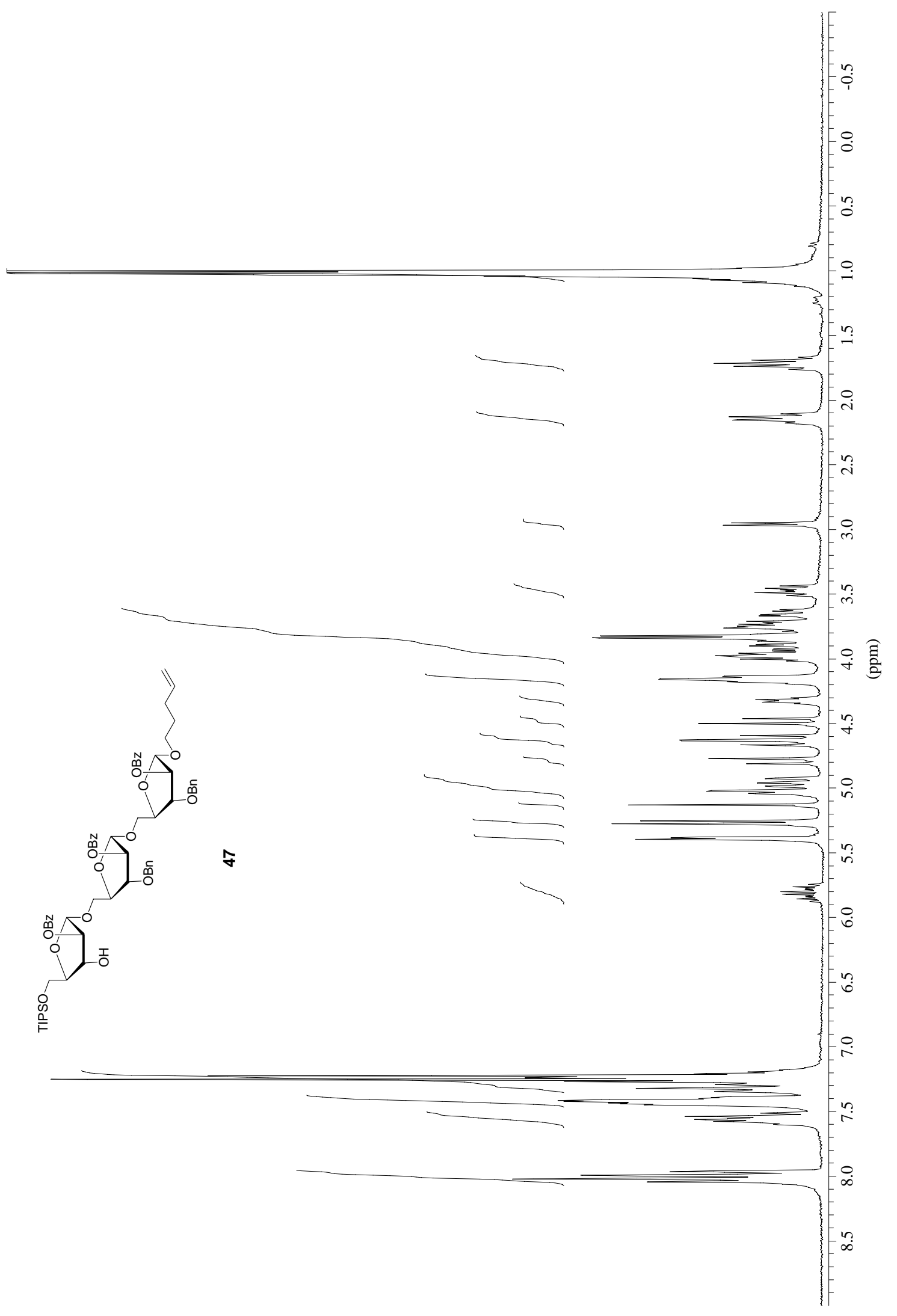




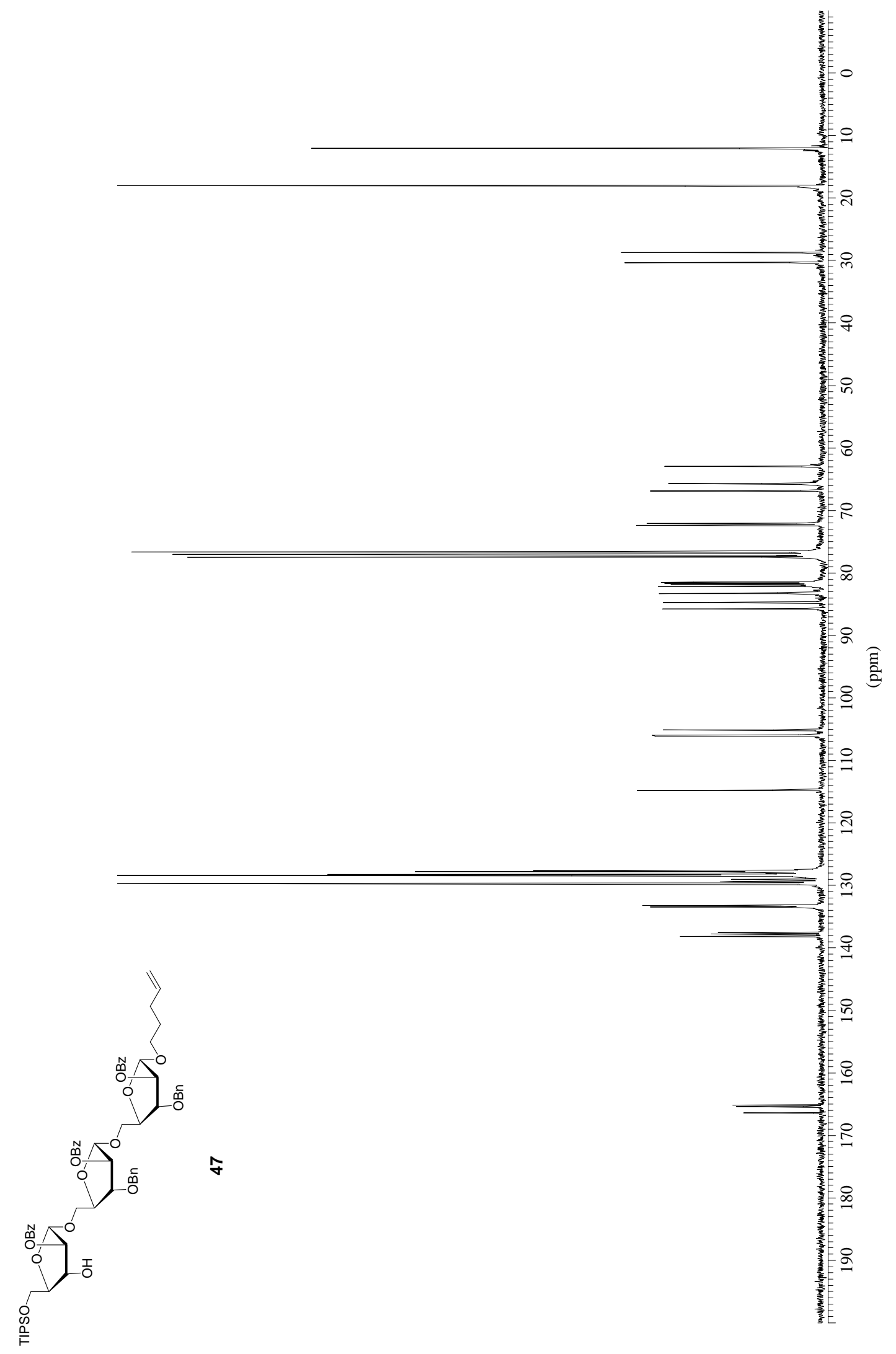




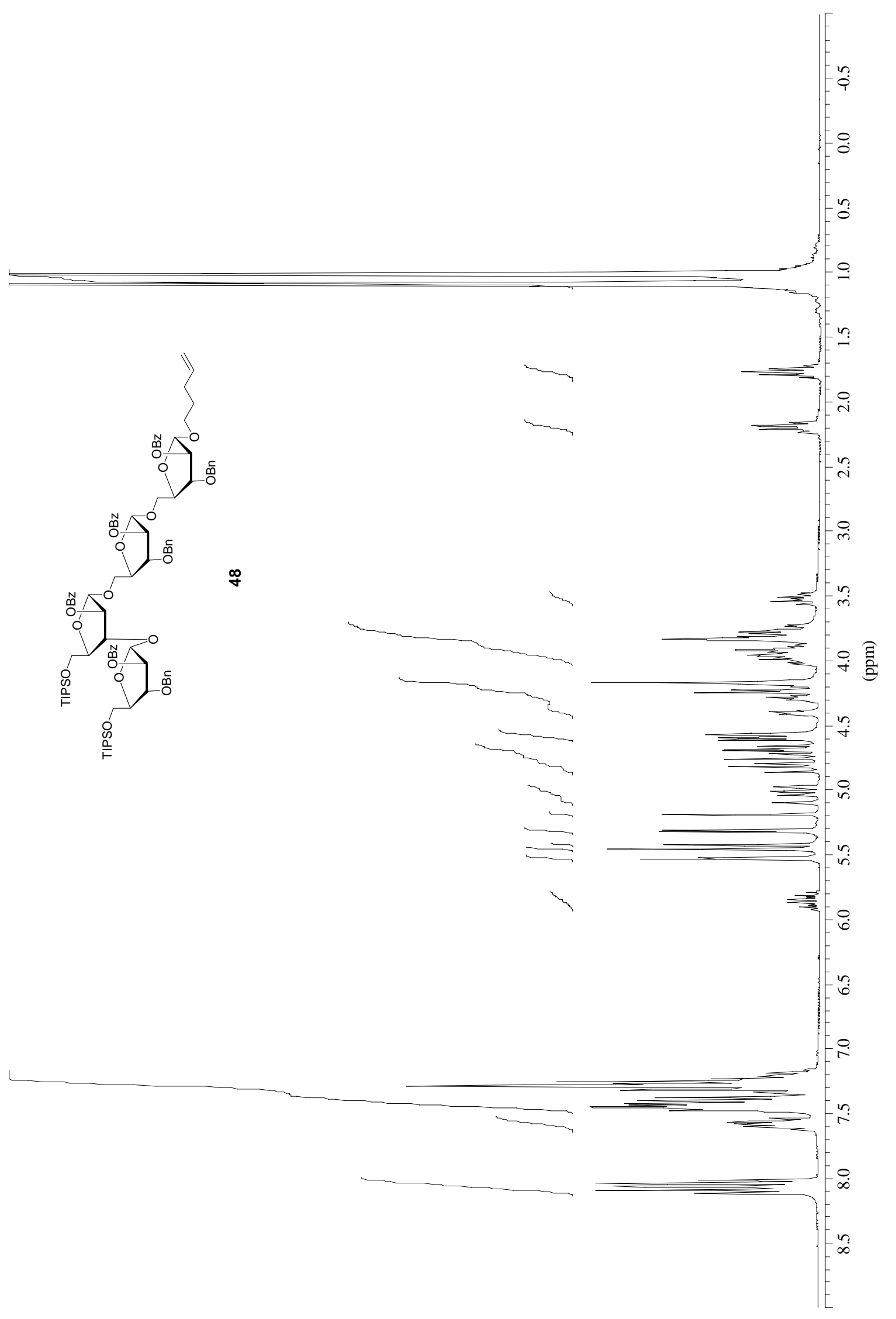




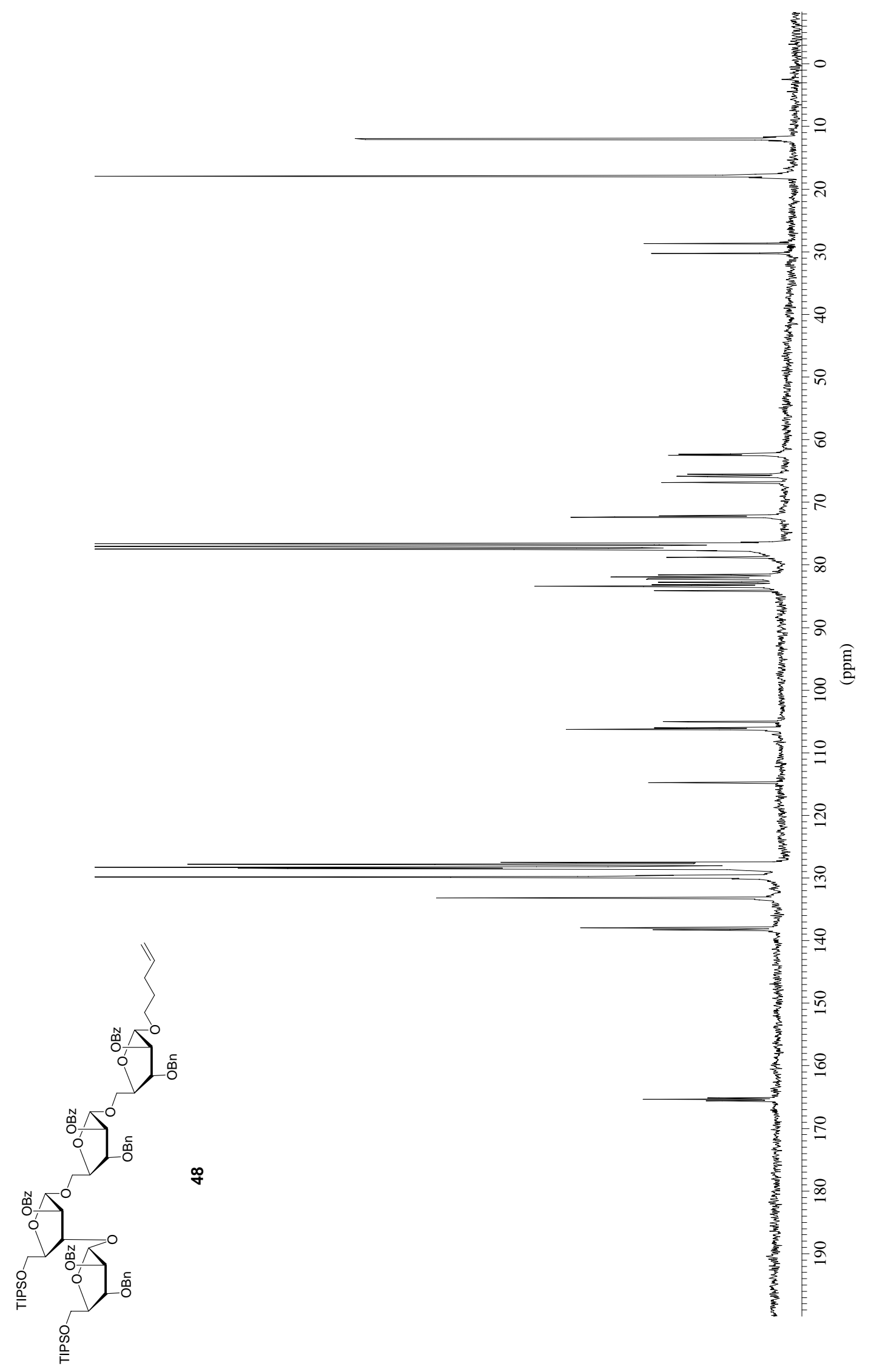




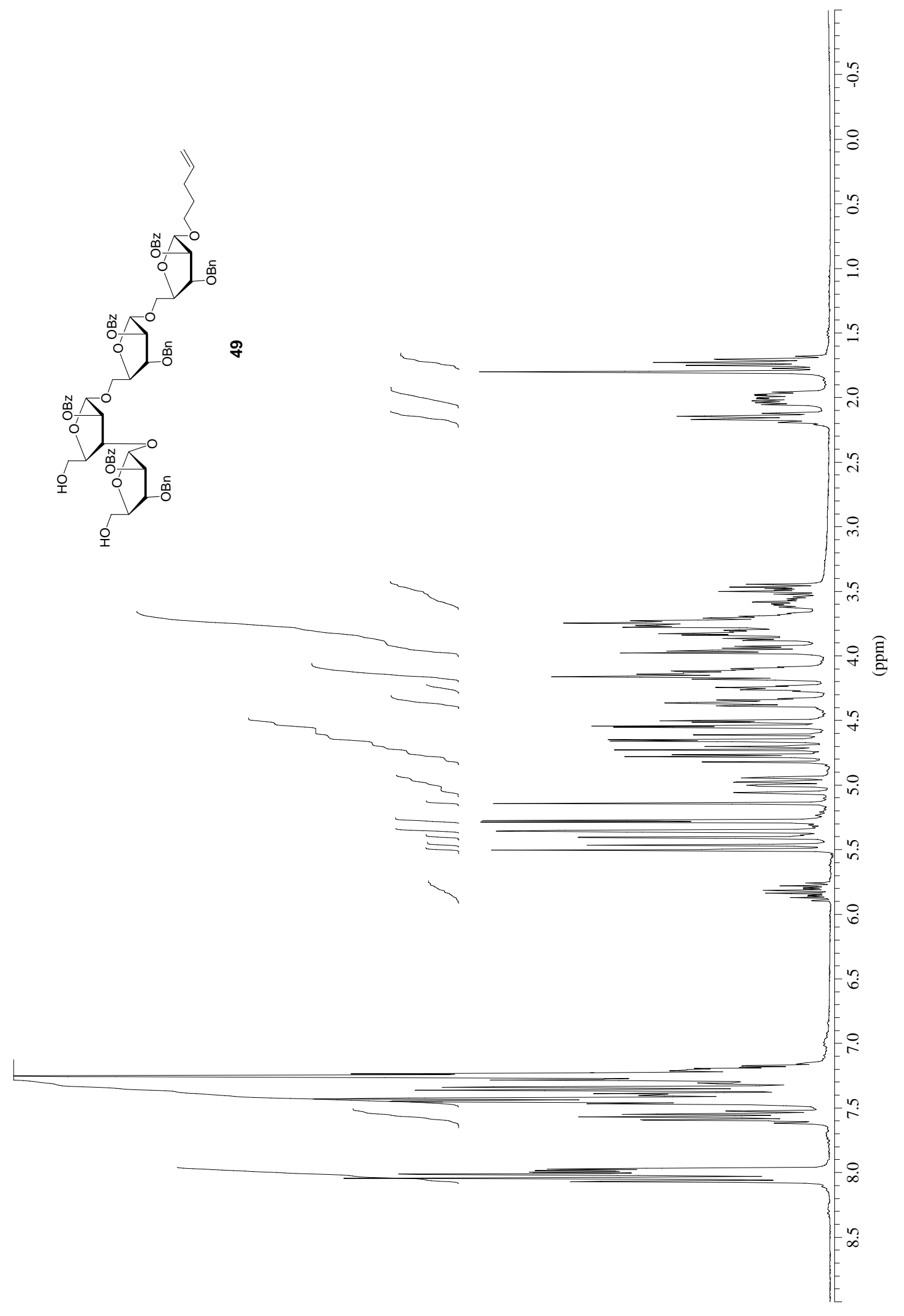




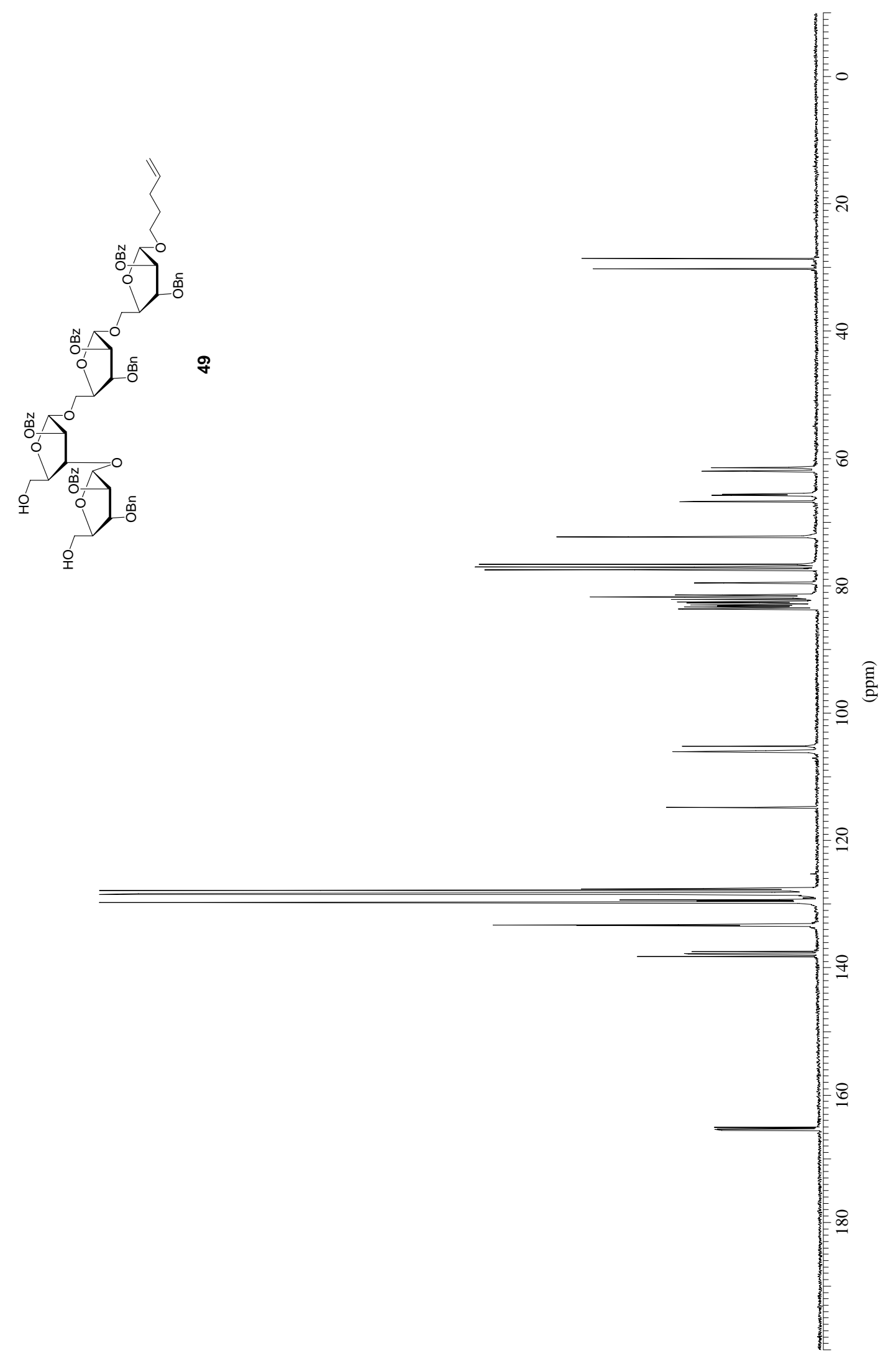




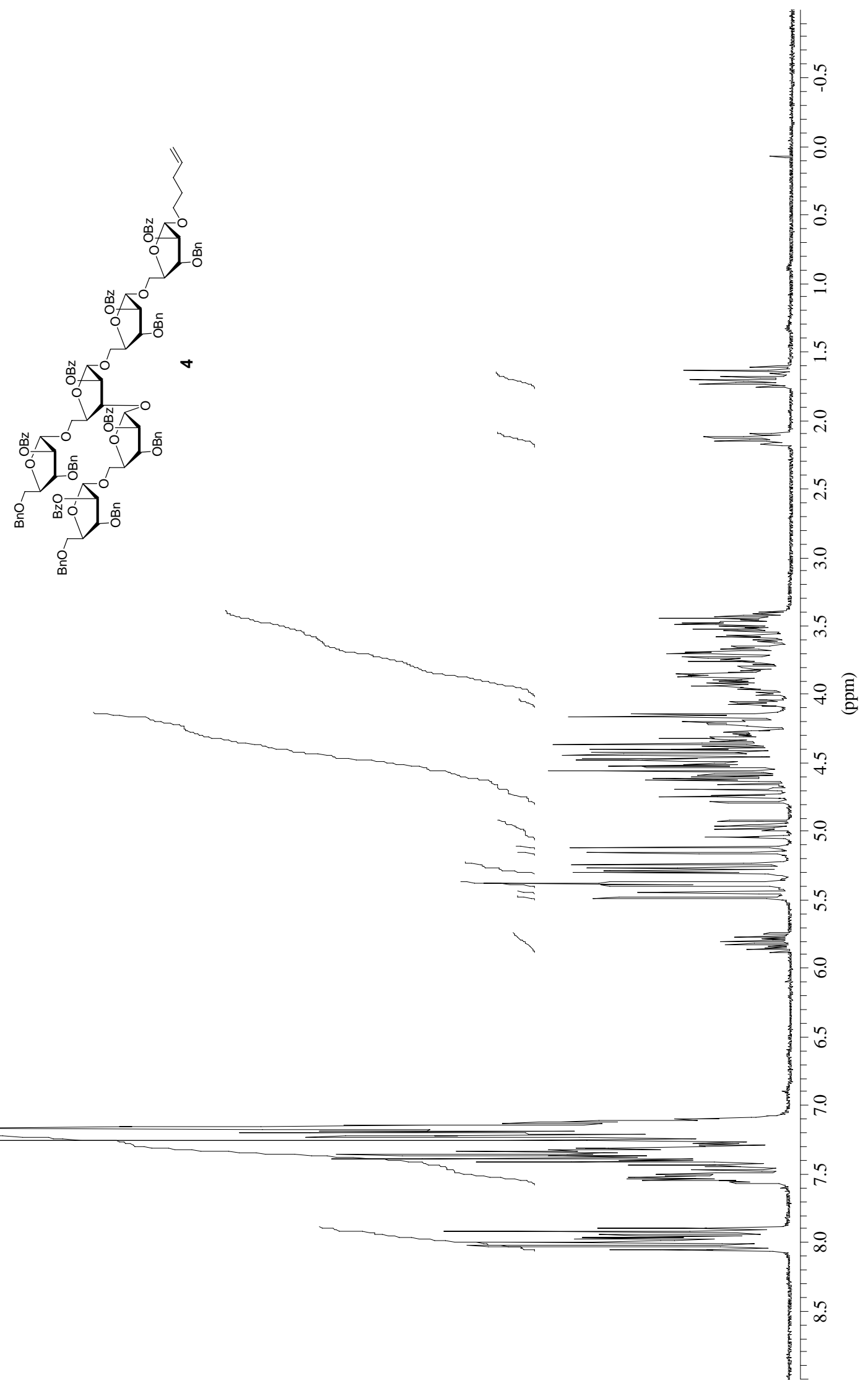



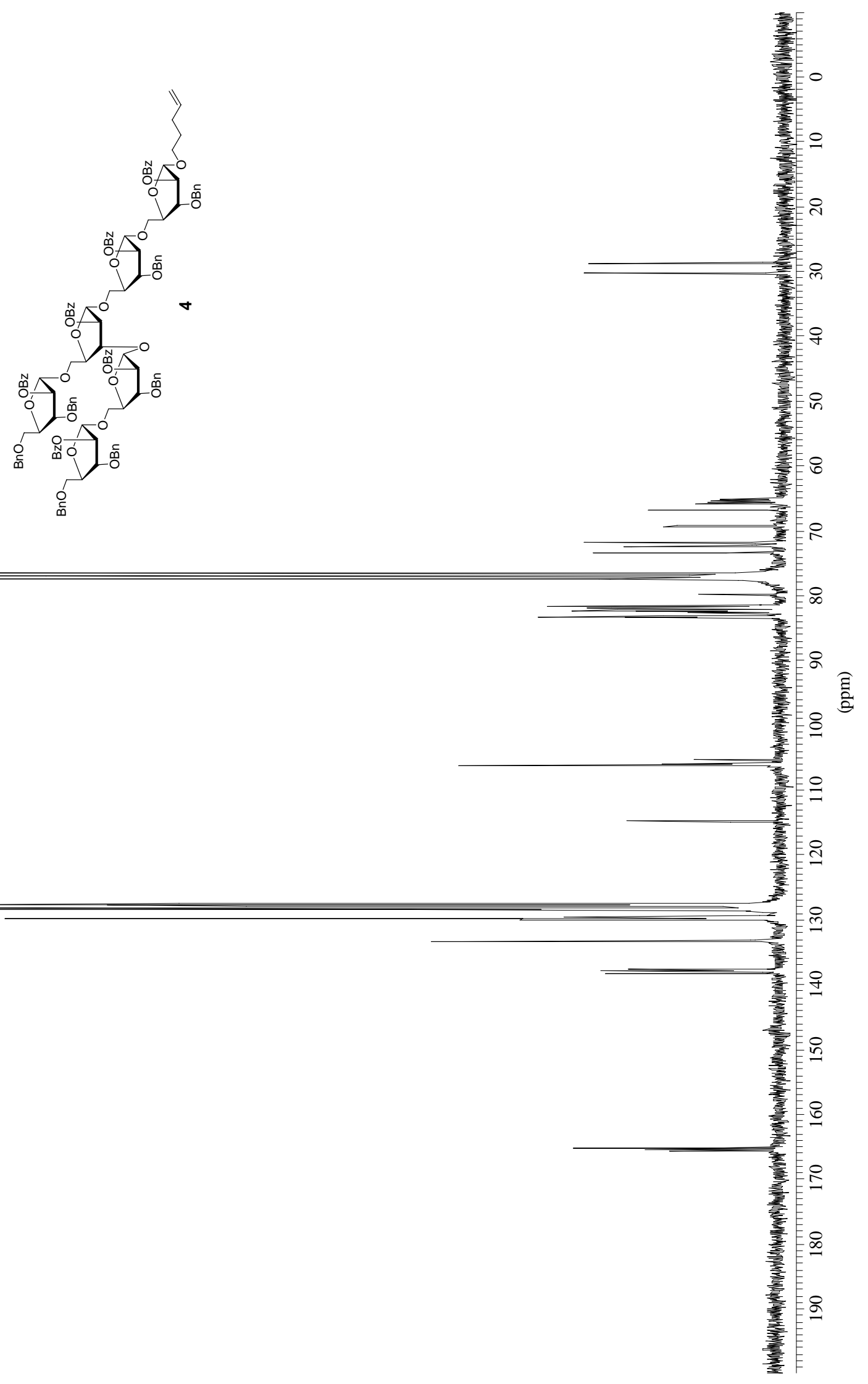


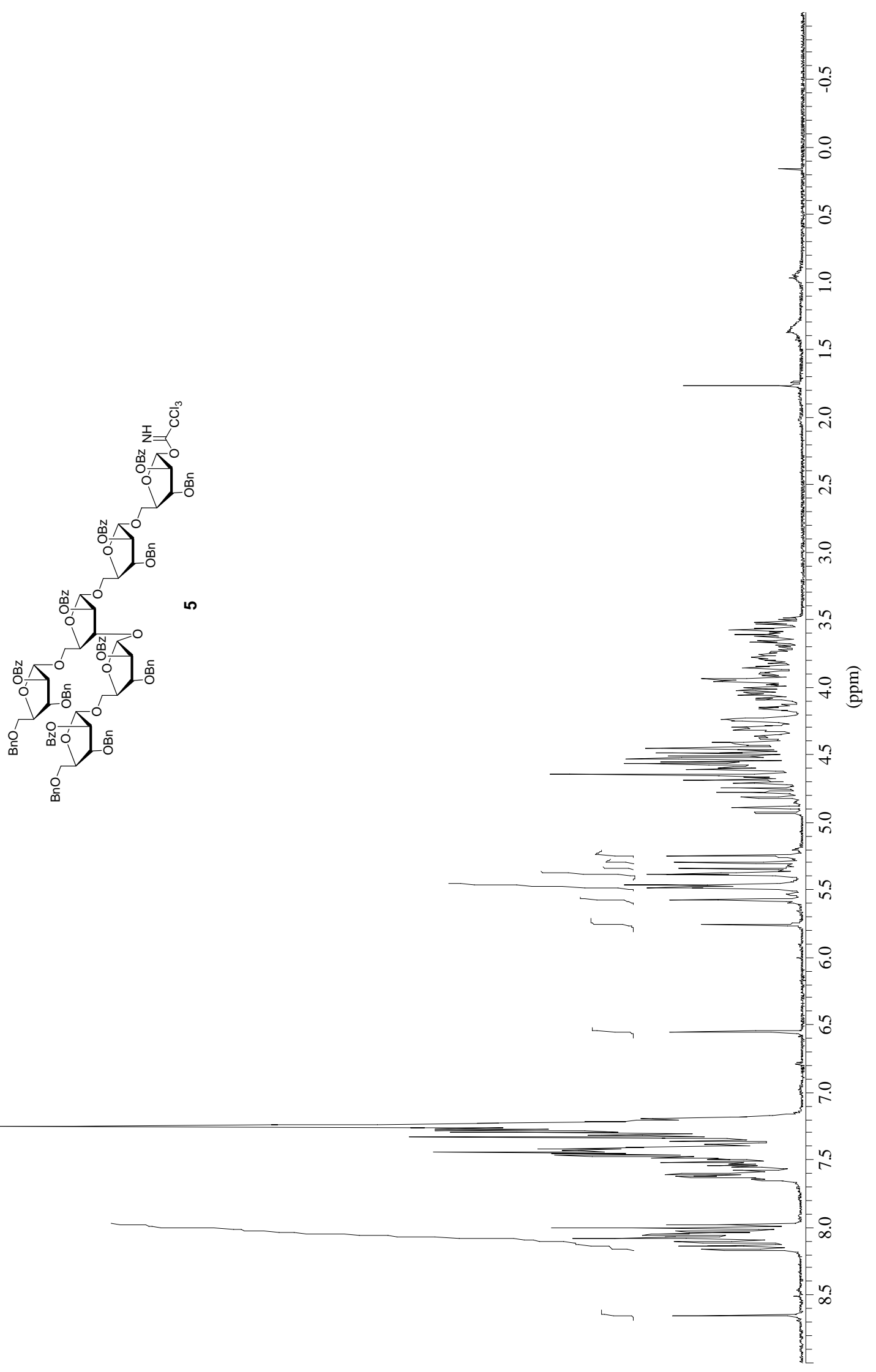



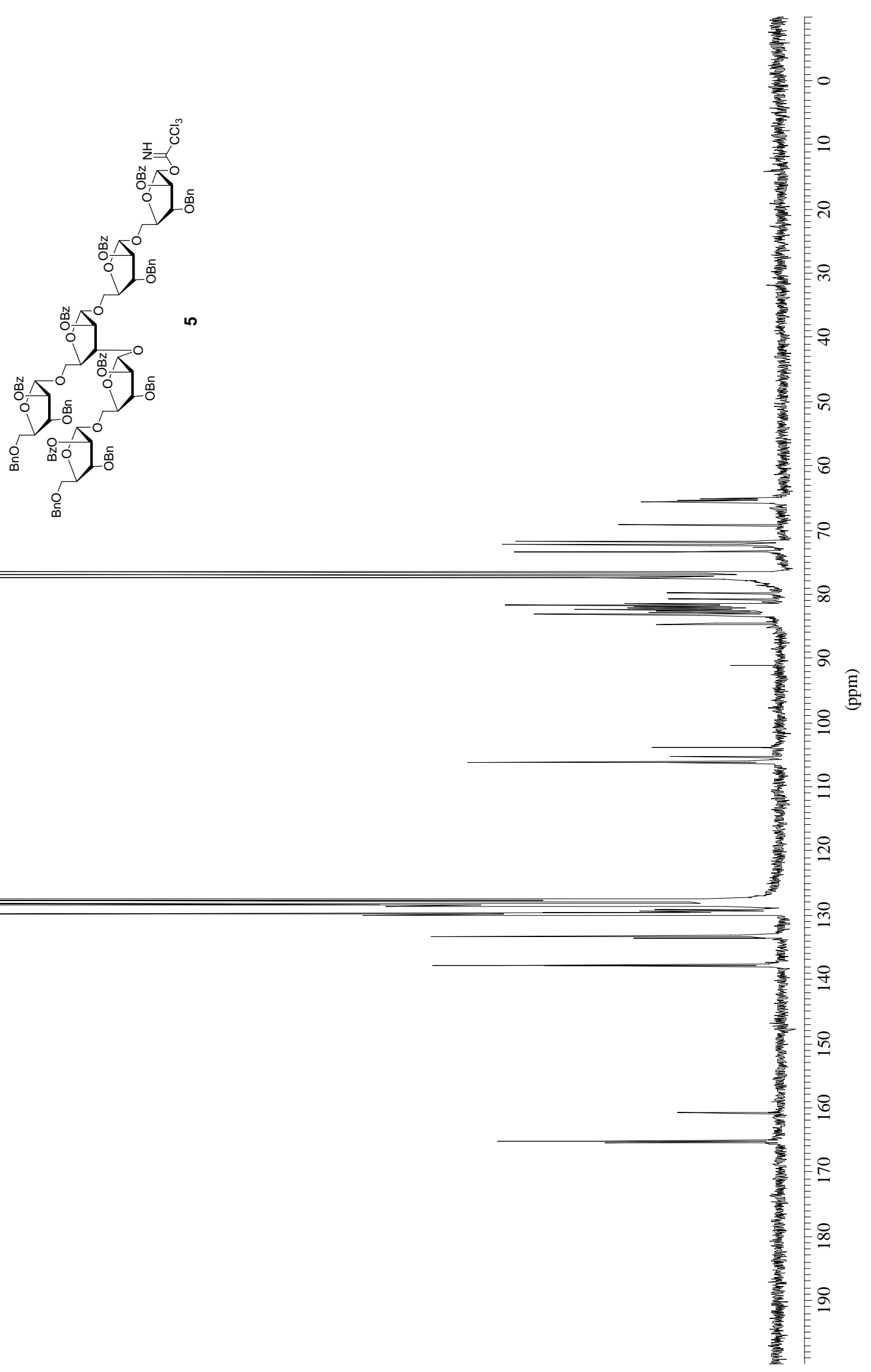

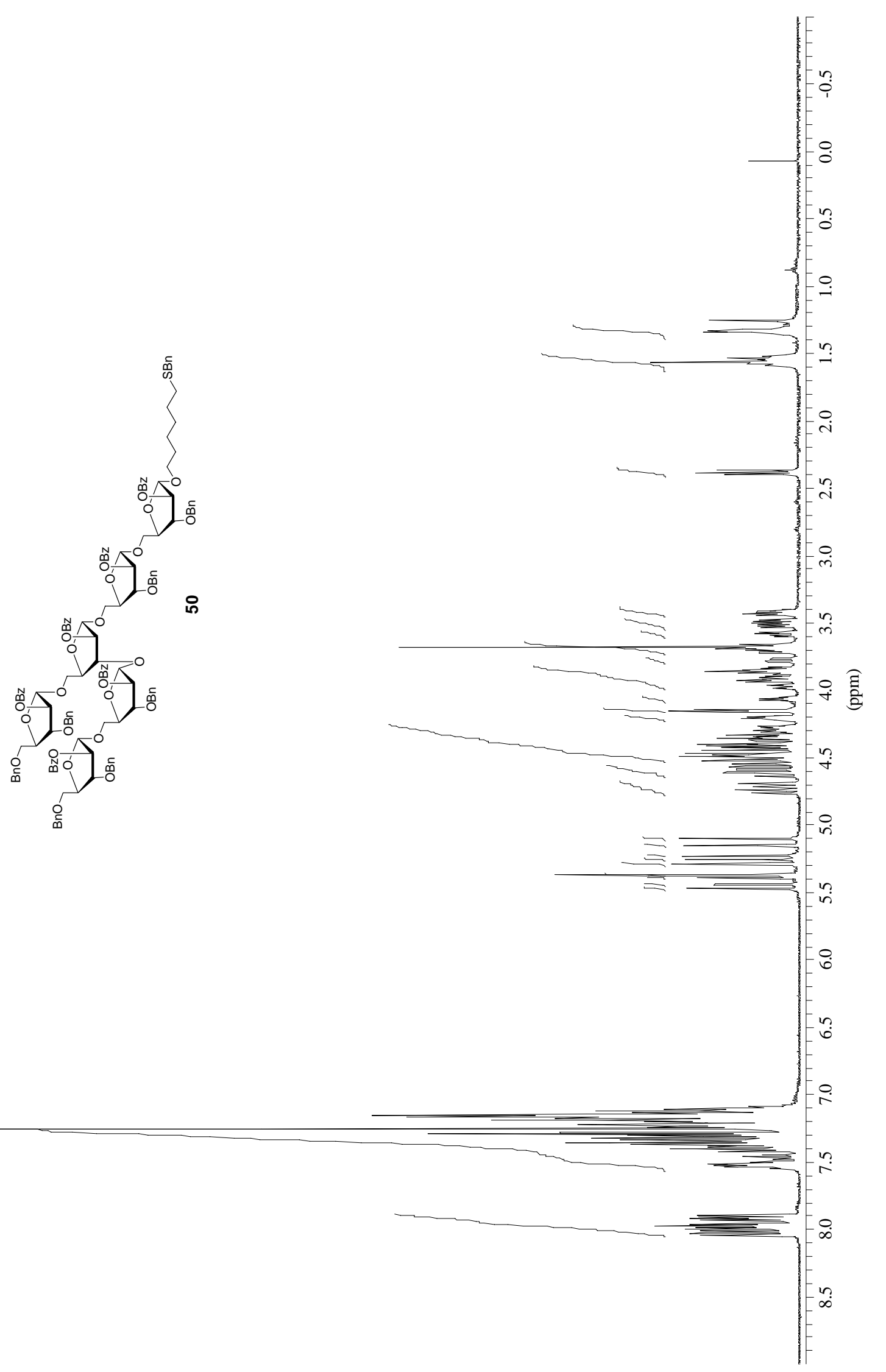

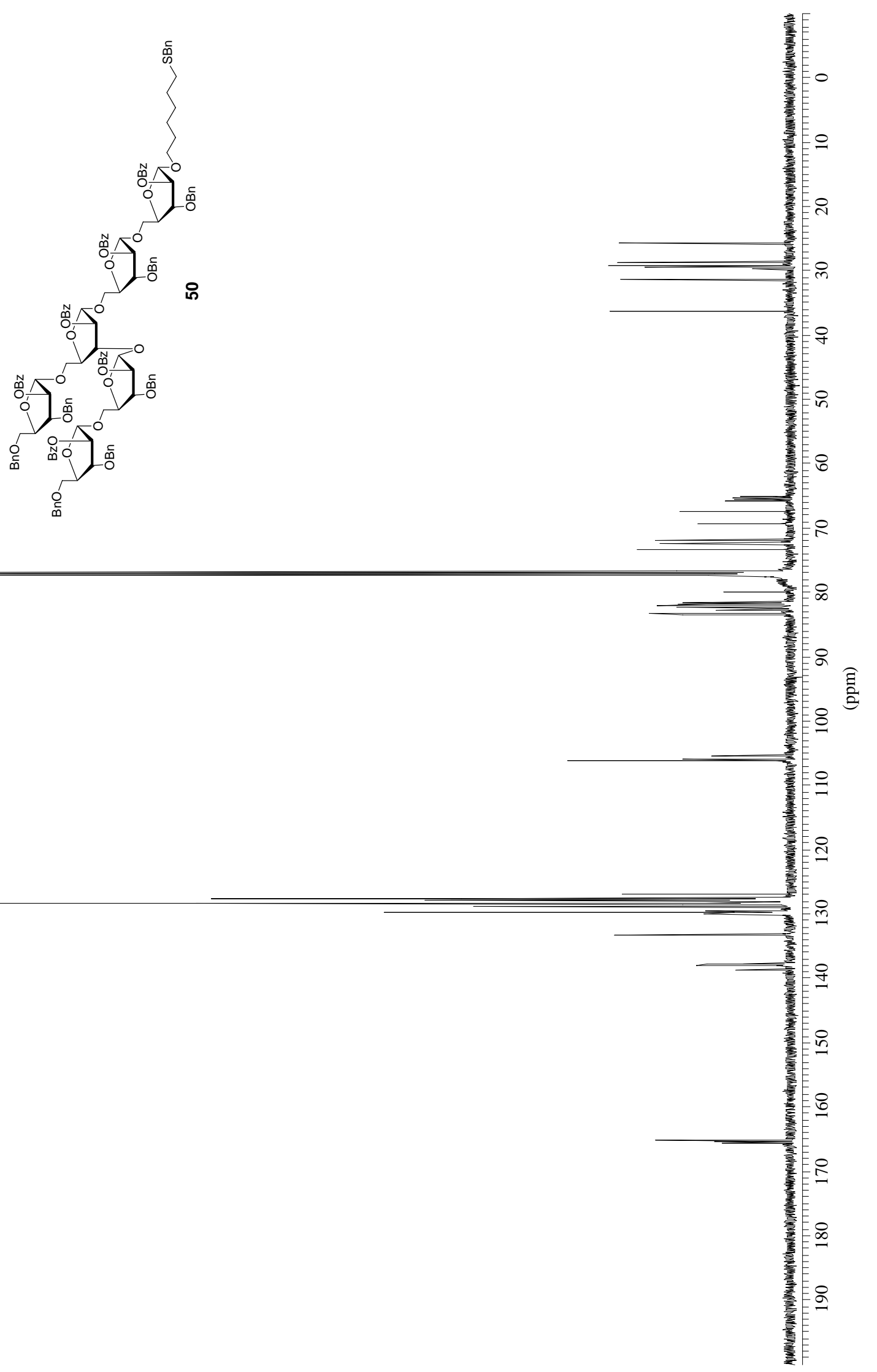


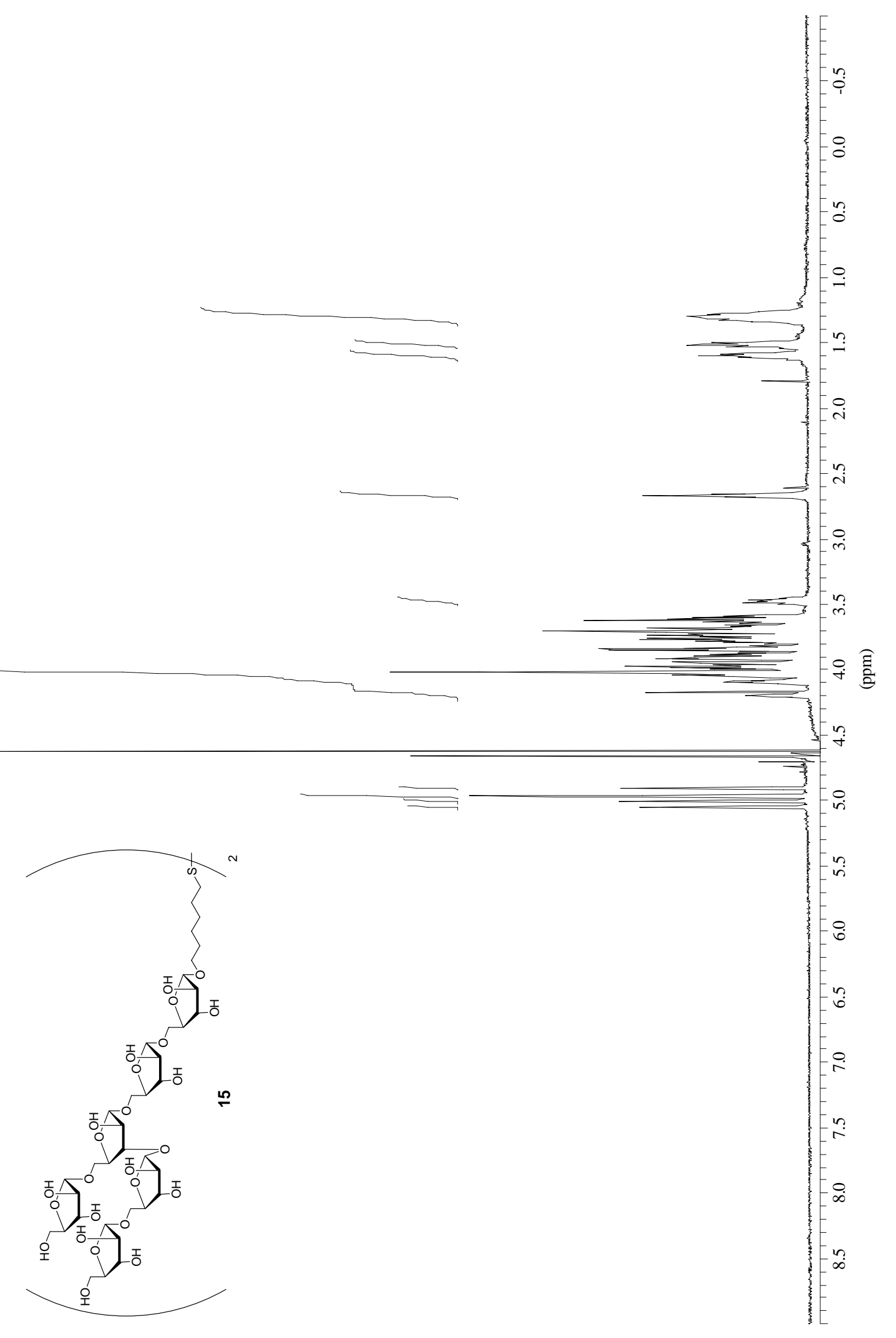




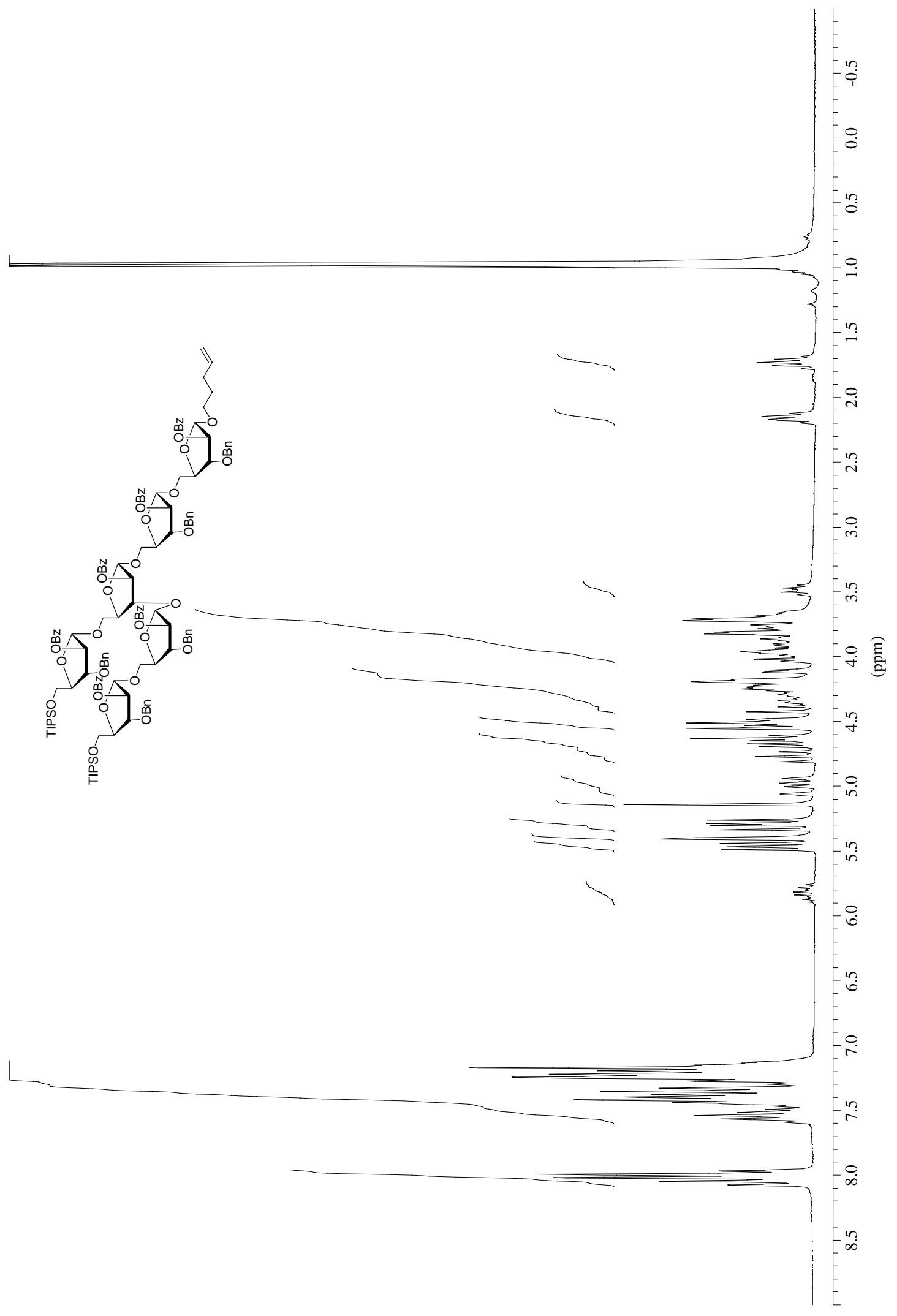




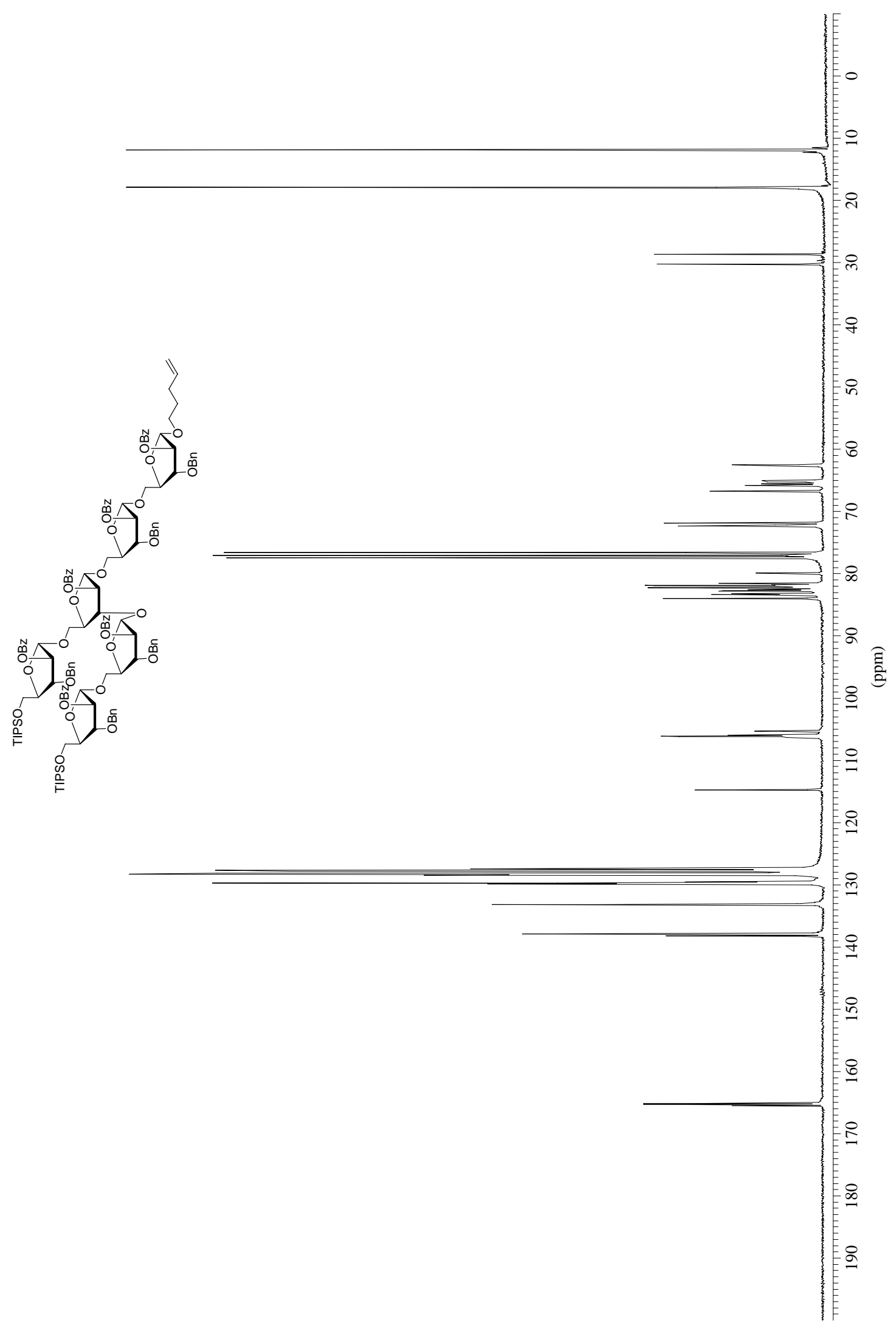




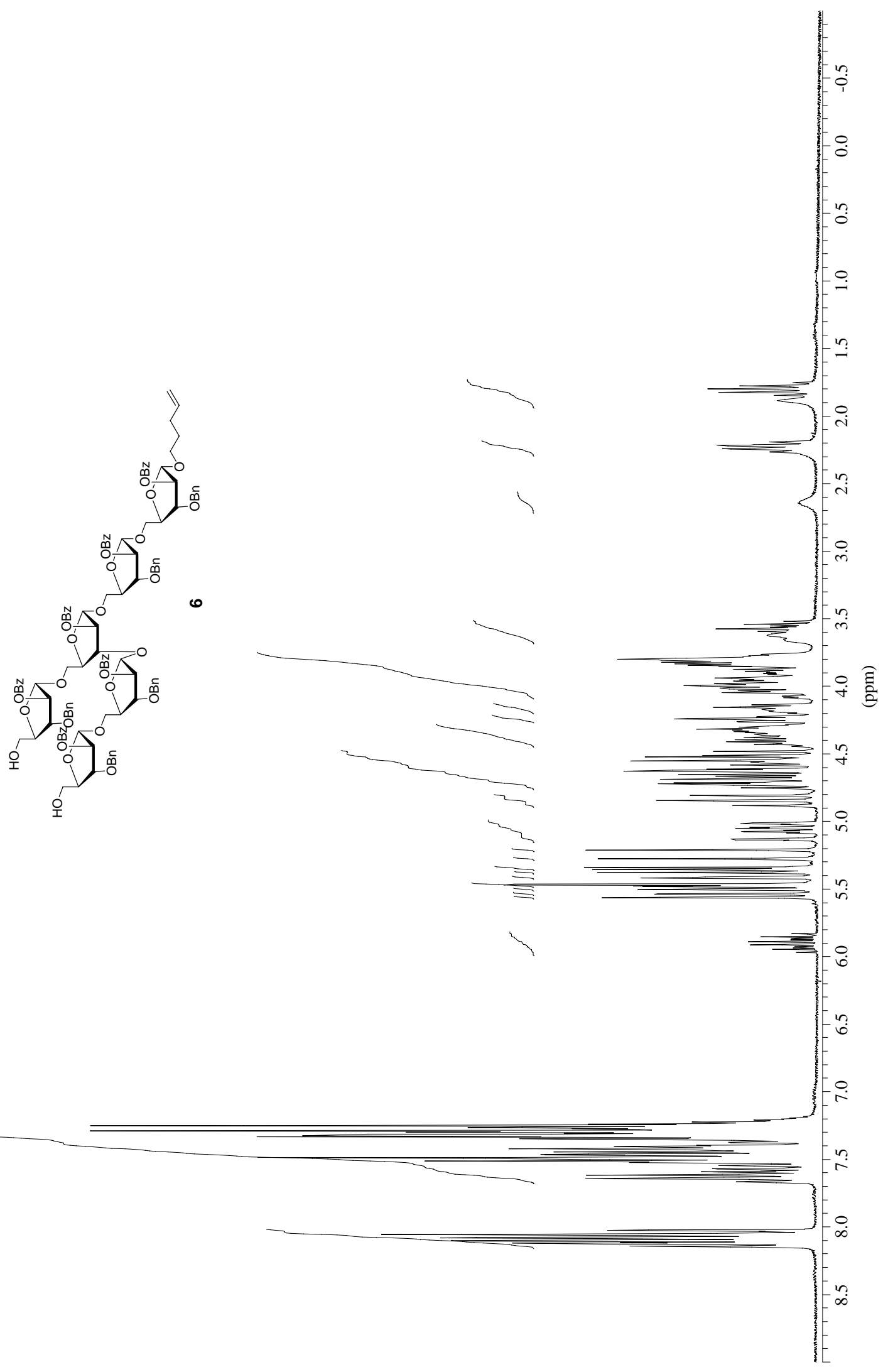



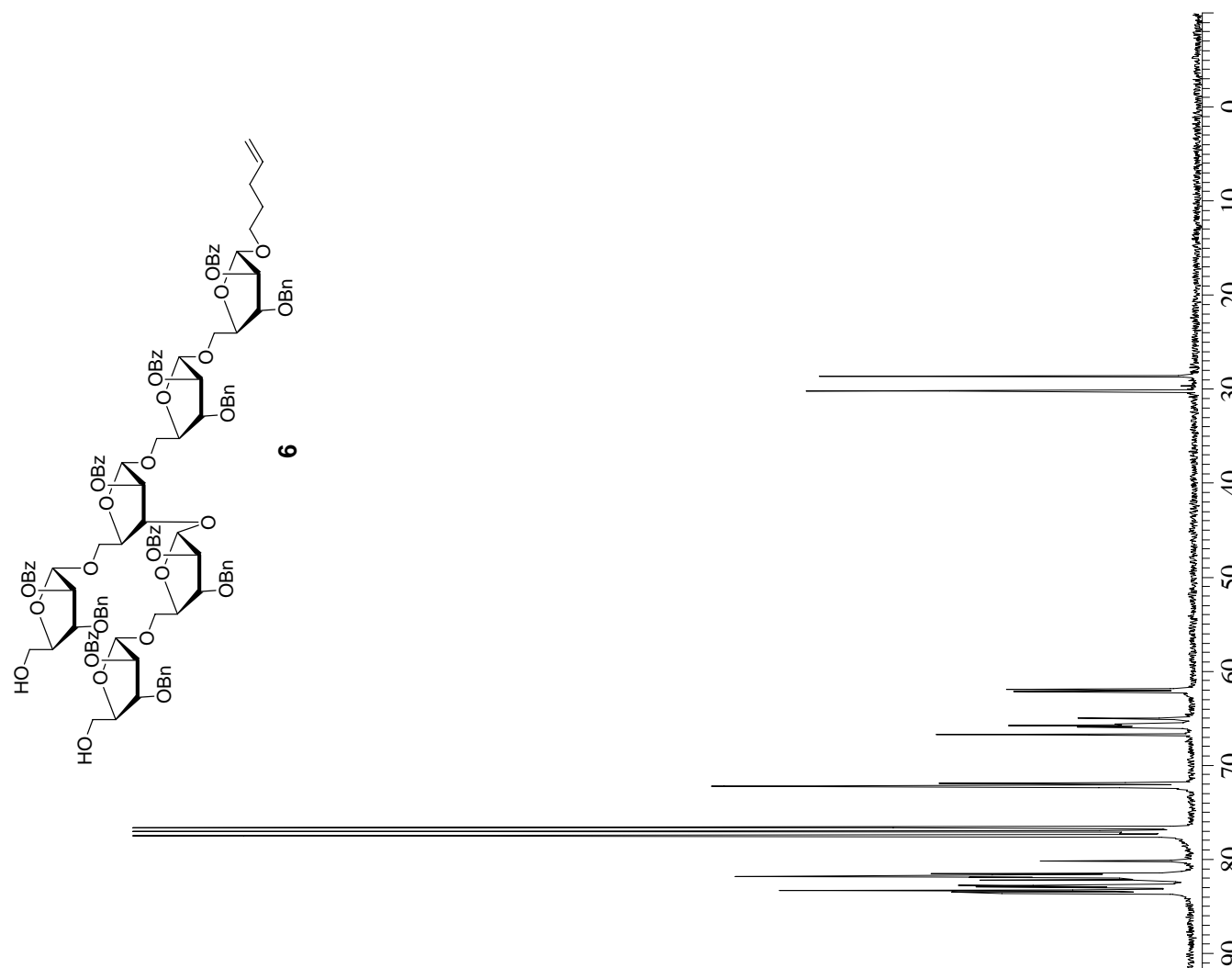


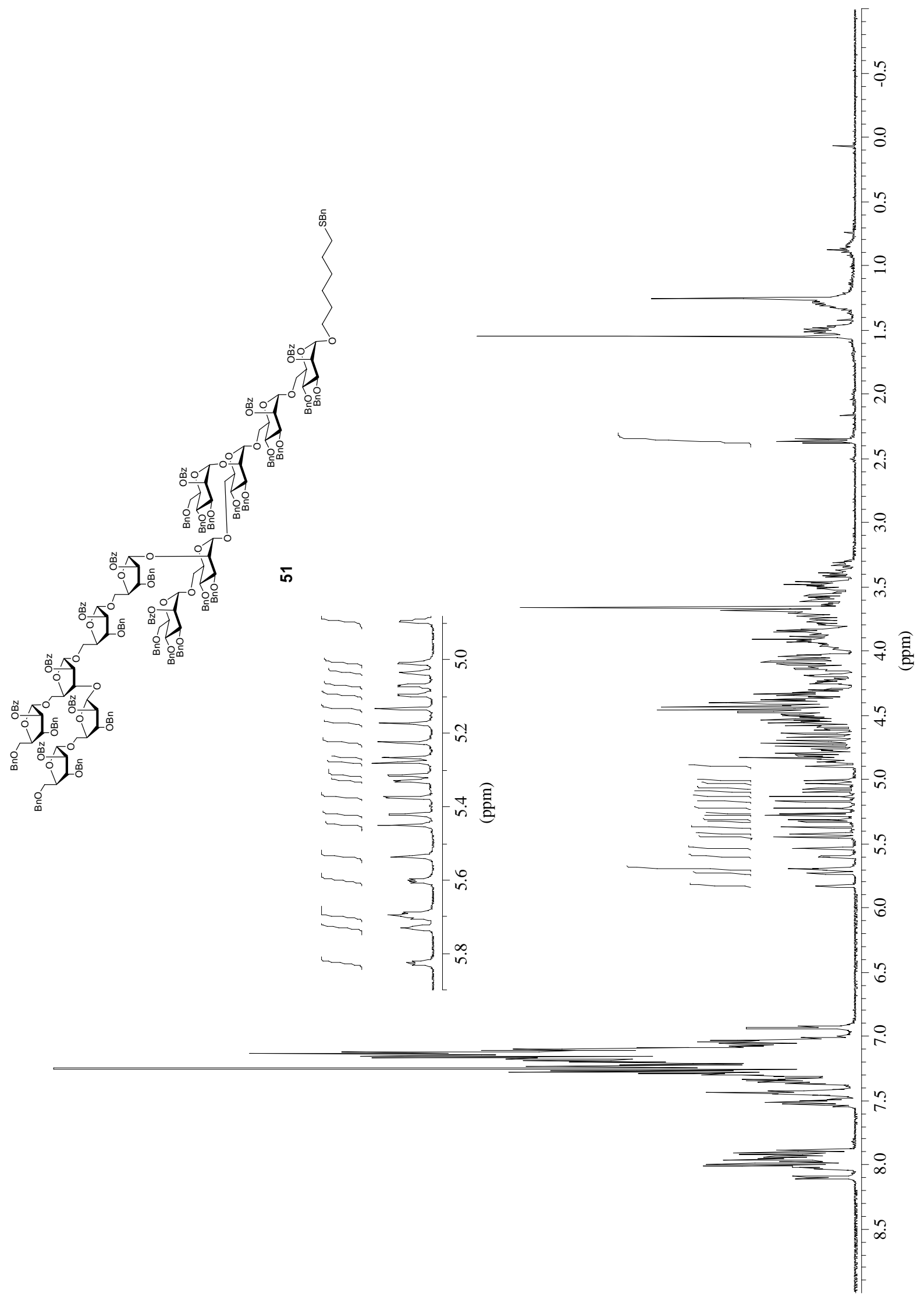




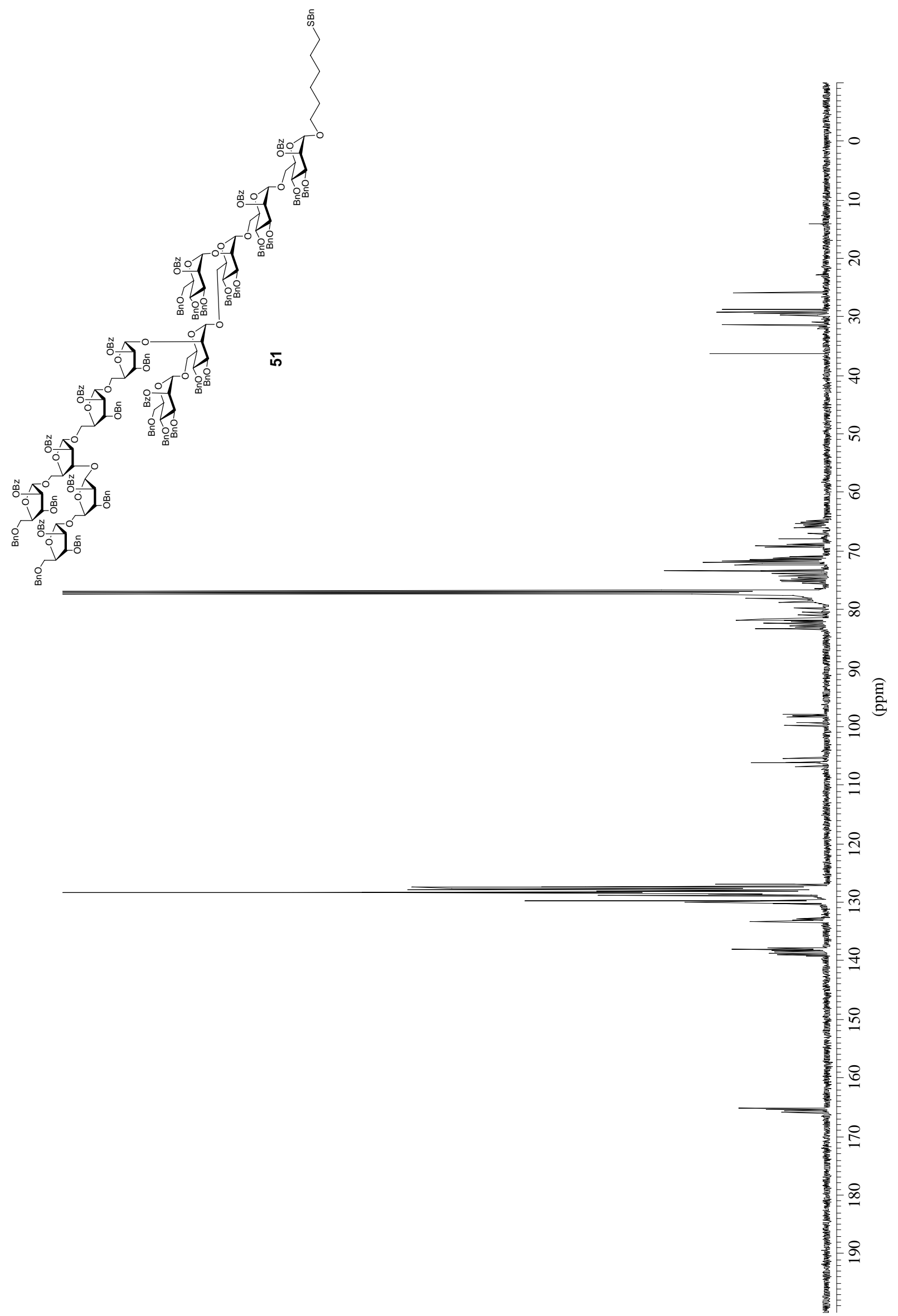



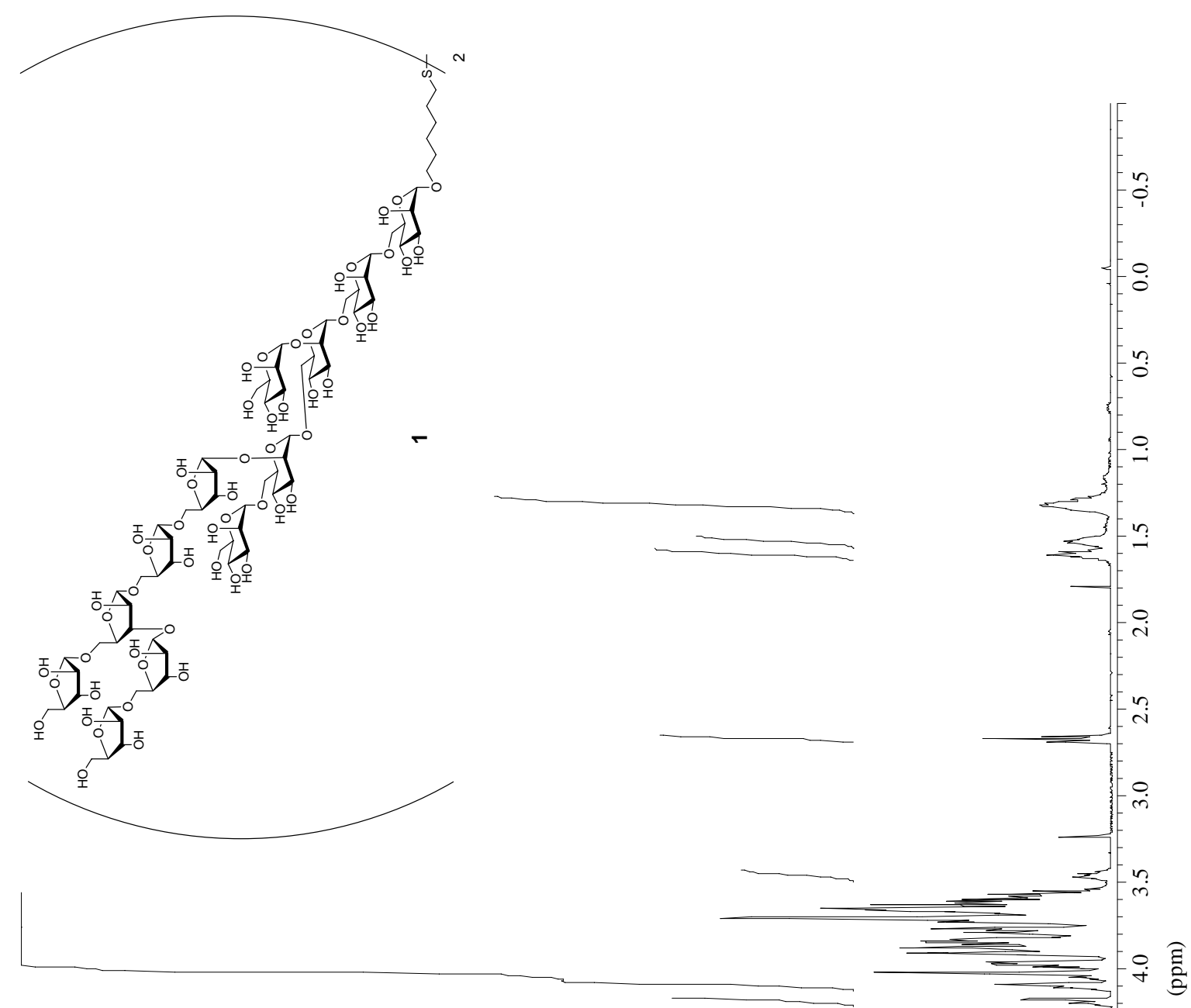

- 㤖
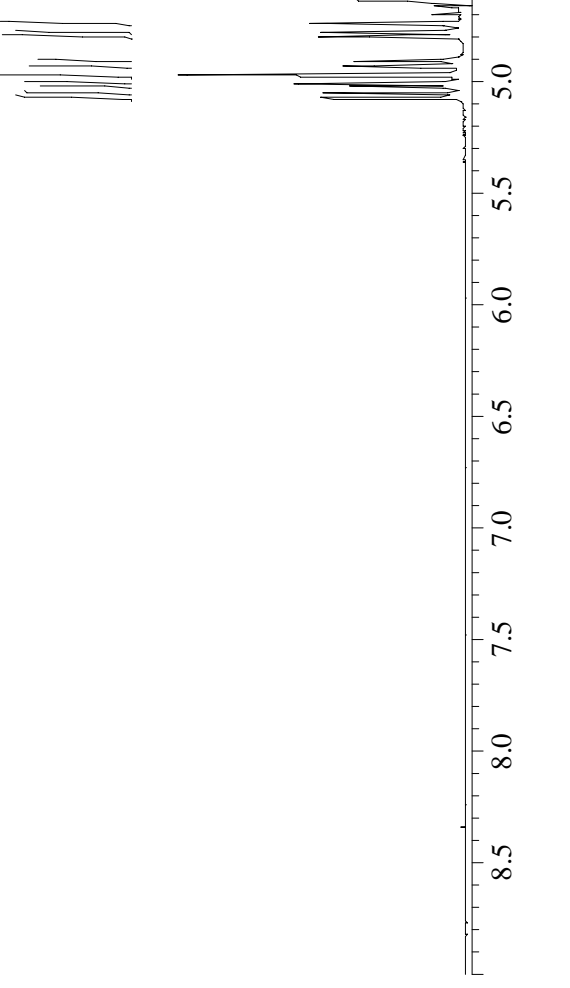


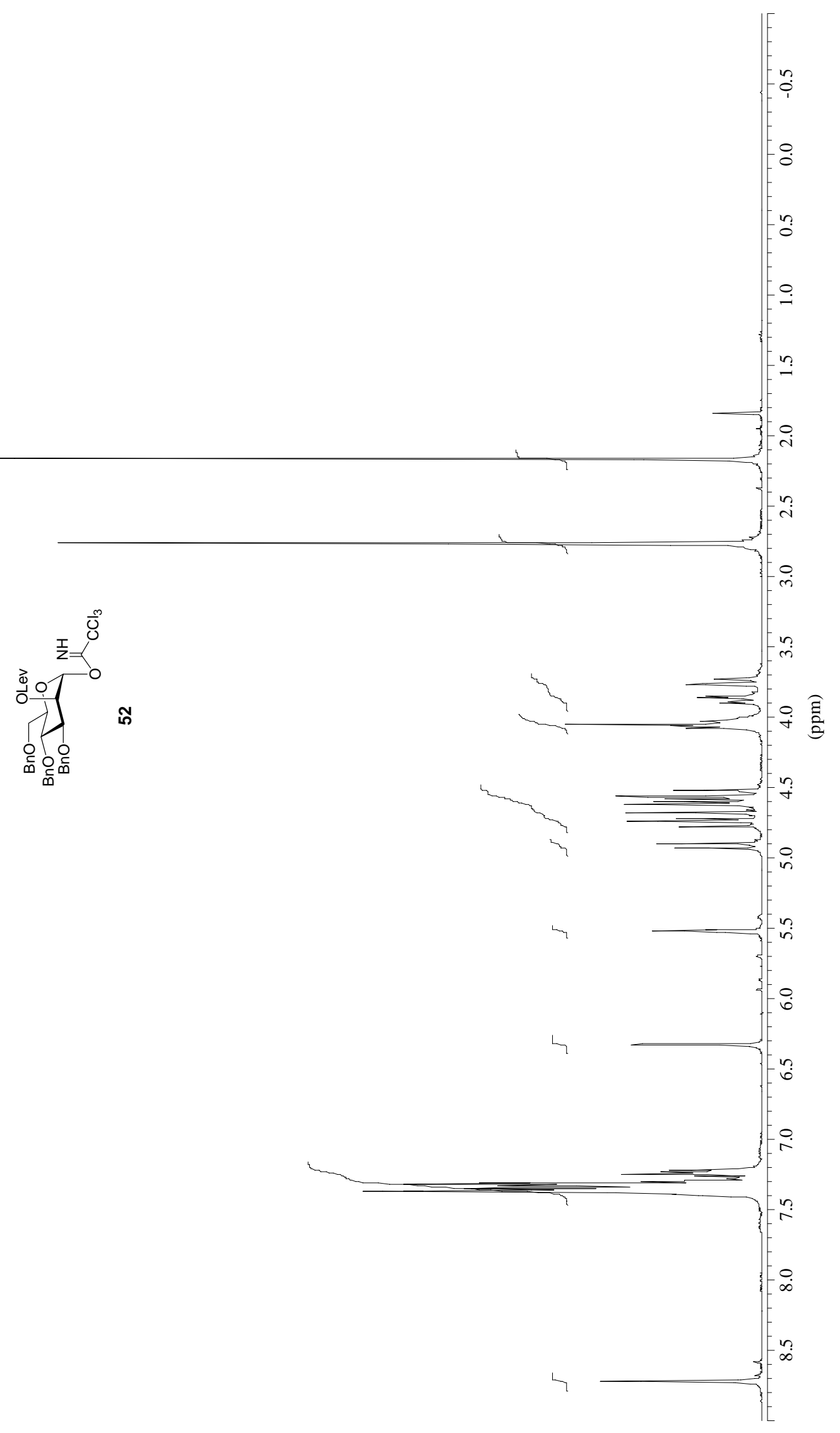




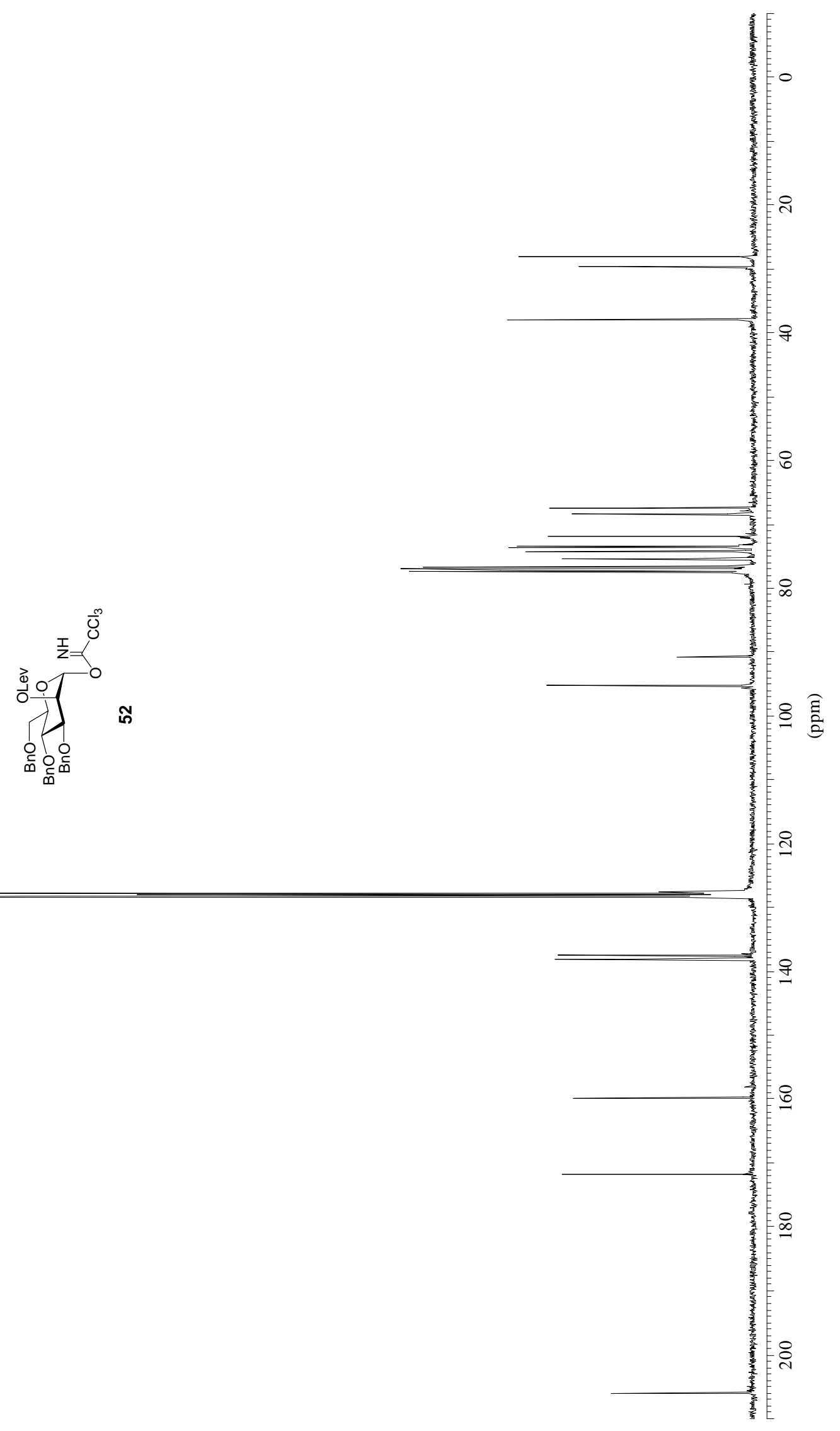




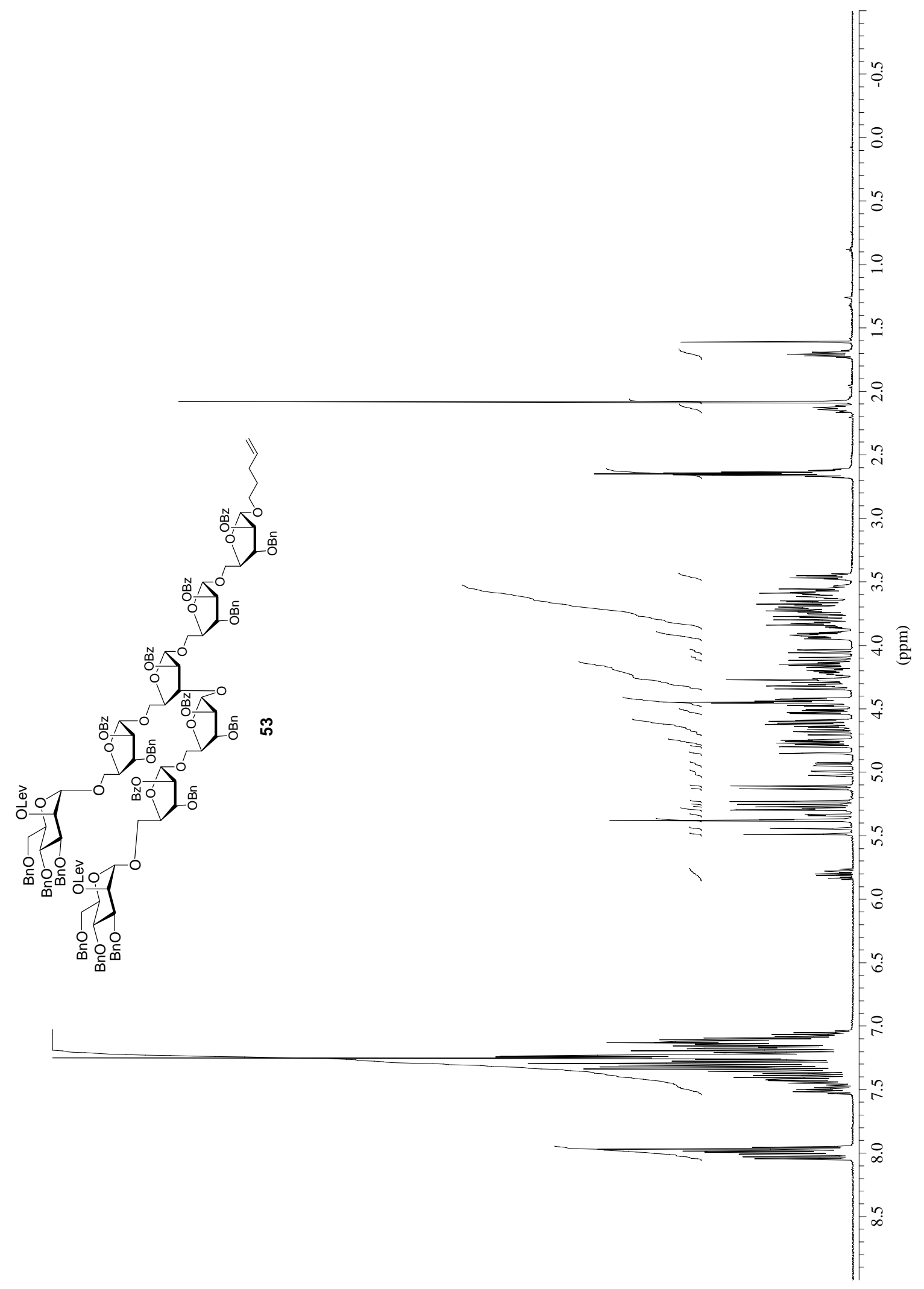




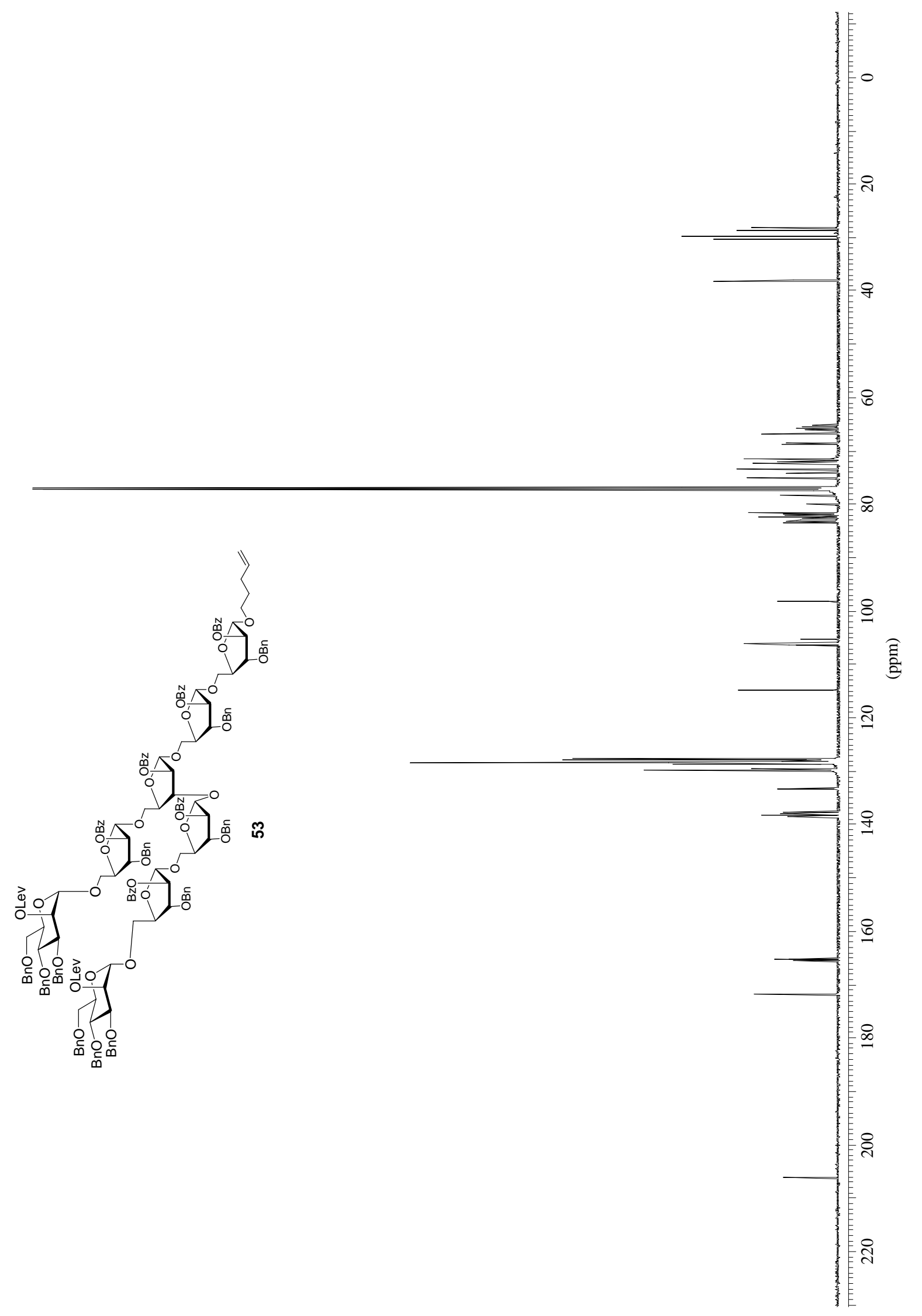



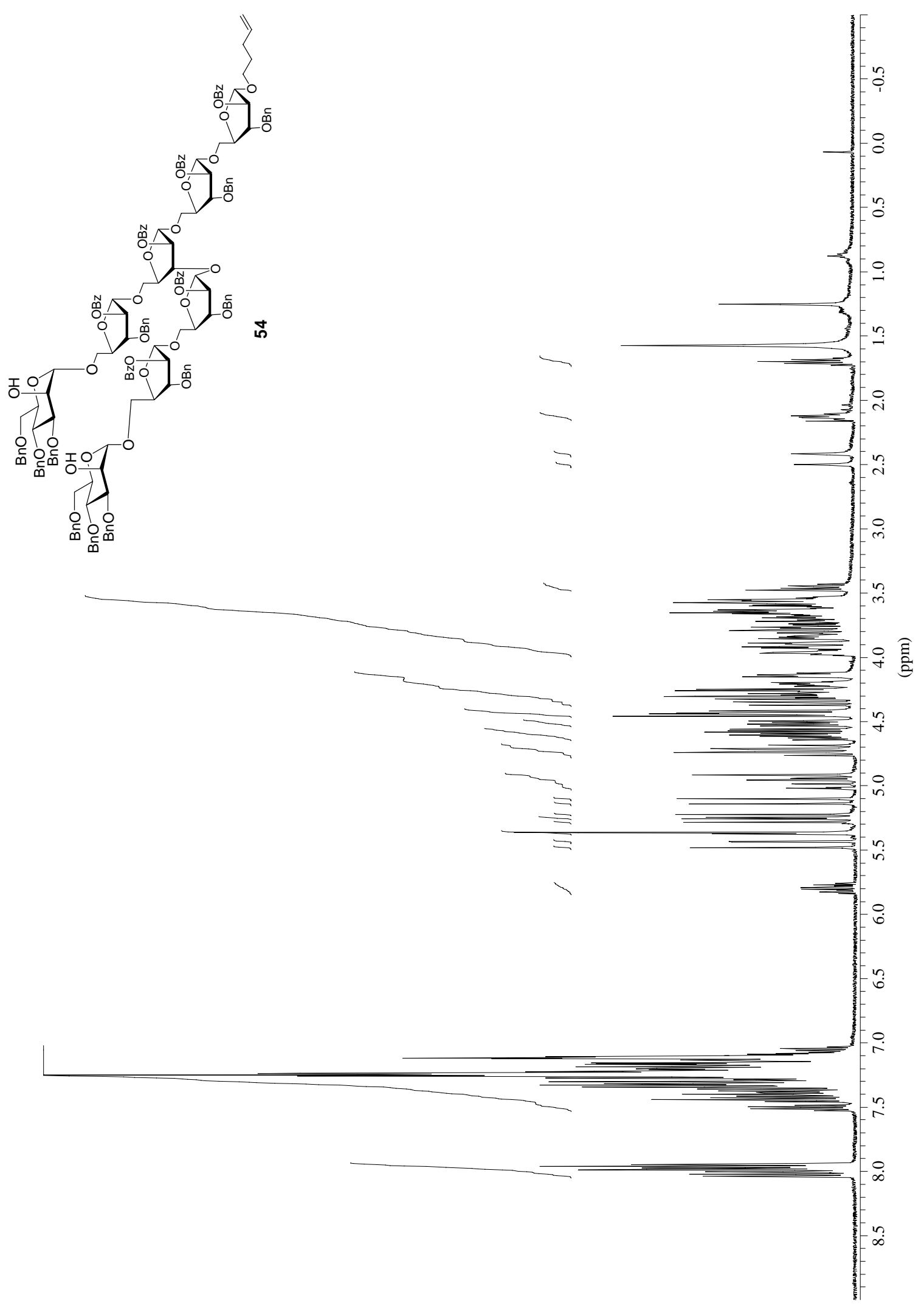

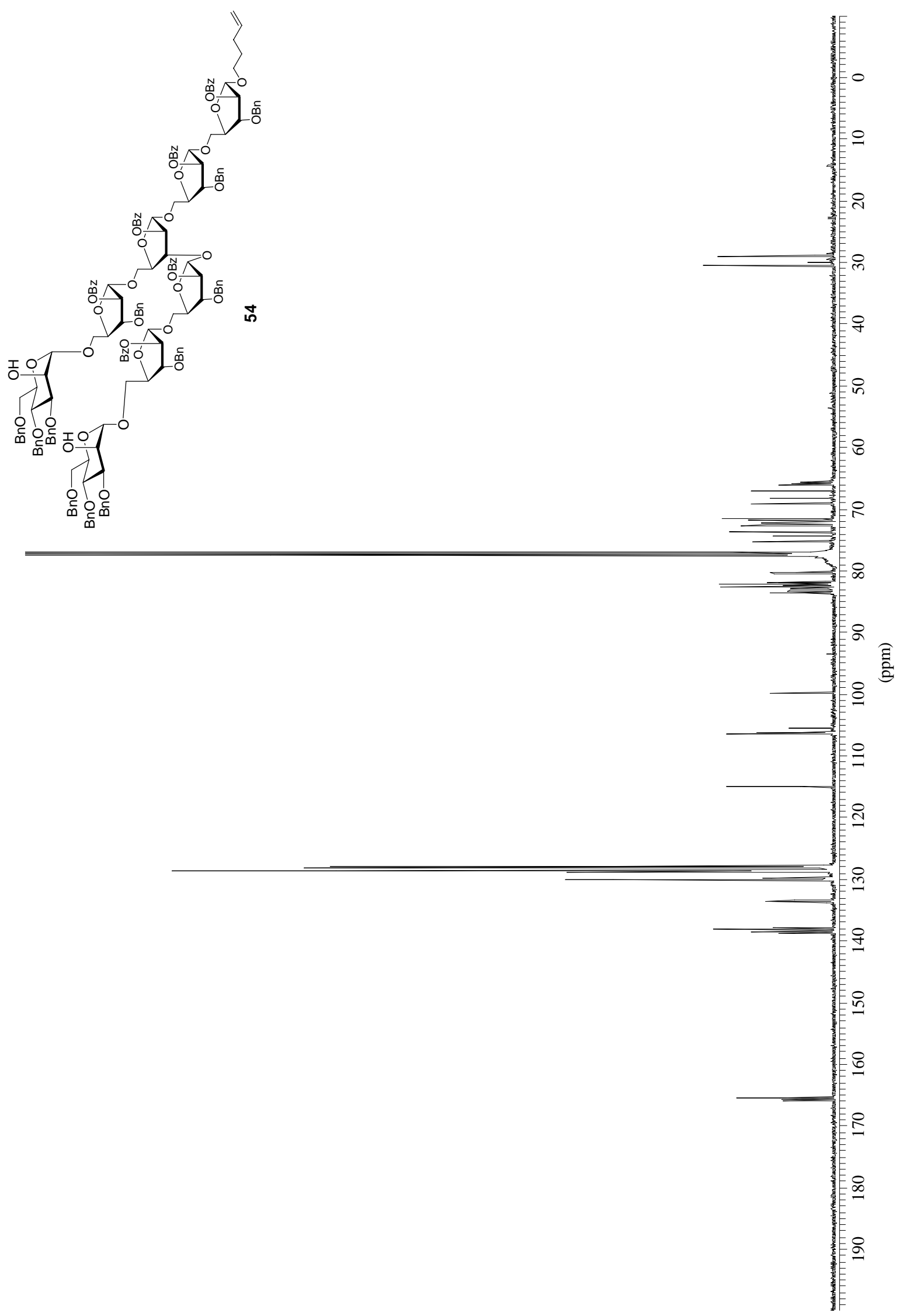